\title{
Probing Mg Migration in Spinel Oxides
}

Ryan D. Bayliss, ${ }^{1,2,3}$ Baris Key, ${ }^{2,4}$ Gopalakrishnan Sai Gautam, ${ }^{2,5,6,7}$ Pieremanuele Canepa, ${ }^{2,6,7}$, Bob Jin Kwon, ${ }^{1}$ Saul H. Lapidus, ${ }^{8}$ Fulya Dogan, ${ }^{4}$ Abdullah A. Adil, ${ }^{1}$ Andrew S. Lipton, ${ }^{9}$ Peter J. Baker, ${ }^{10}$ Gerbrand Ceder, ${ }^{2,6,7}$ John T. Vaughey ${ }^{2,4}$ and Jordi Cabana ${ }^{1,2 *}$

${ }^{1}$ Department of Chemistry, University of Illinois at Chicago

${ }^{2}$ Joint Center for Energy Storage Research, Argonne National Laboratory

${ }^{3}$ Department of Materials, University of Oxford

${ }^{4}$ Chemical Science and Engineering, Argonne National Laboratory

${ }^{5}$ Department of Materials Science and Engineering, Massachusetts Institute of Technology

${ }^{6}$ Materials Science Division, Lawrence Berkeley National Laboratory

${ }^{7}$ Department of Materials Science and Engineering, University of California

${ }^{8}$ Advanced Photon Source, Argonne National Laboratory

${ }^{9}$ Environmental Molecular Sciences Laboratory, Pacific Northwest National Laboratory

${ }^{10}$ ISIS Pulsed Neutron and Muon Source, Rutherford Appleton Laboratory

*Correspondence J. C. (jcabana@ uic.edu)

\section{Supporting Information}


Figure S1: Rietveld refinement of S-XRD of $\mathrm{MgMn}_{2} \mathrm{O}_{4}$

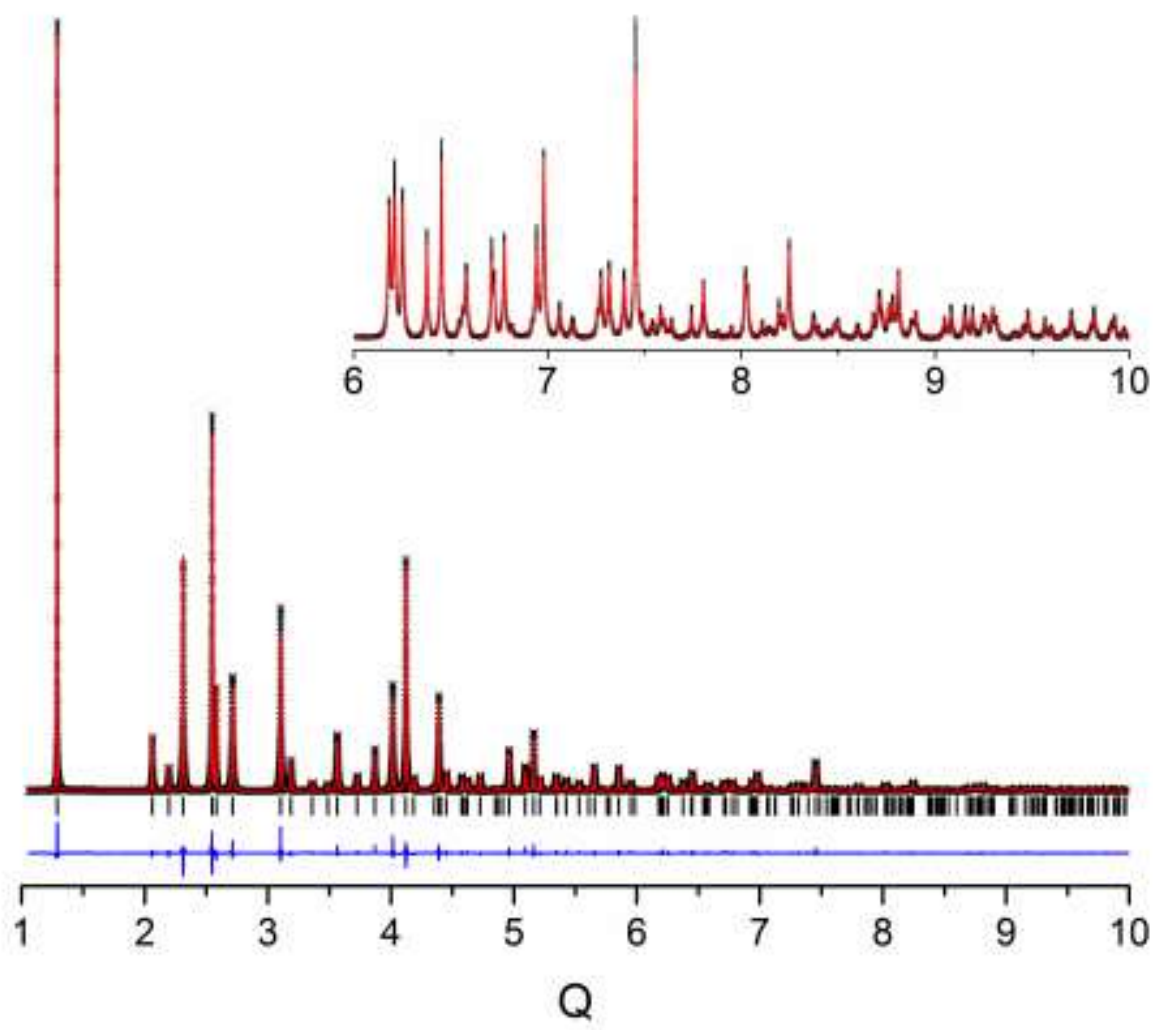


Figure S2: Rietveld refinement of TOF-NPD of $\mathrm{MgMn}_{2} \mathrm{O}_{4}$

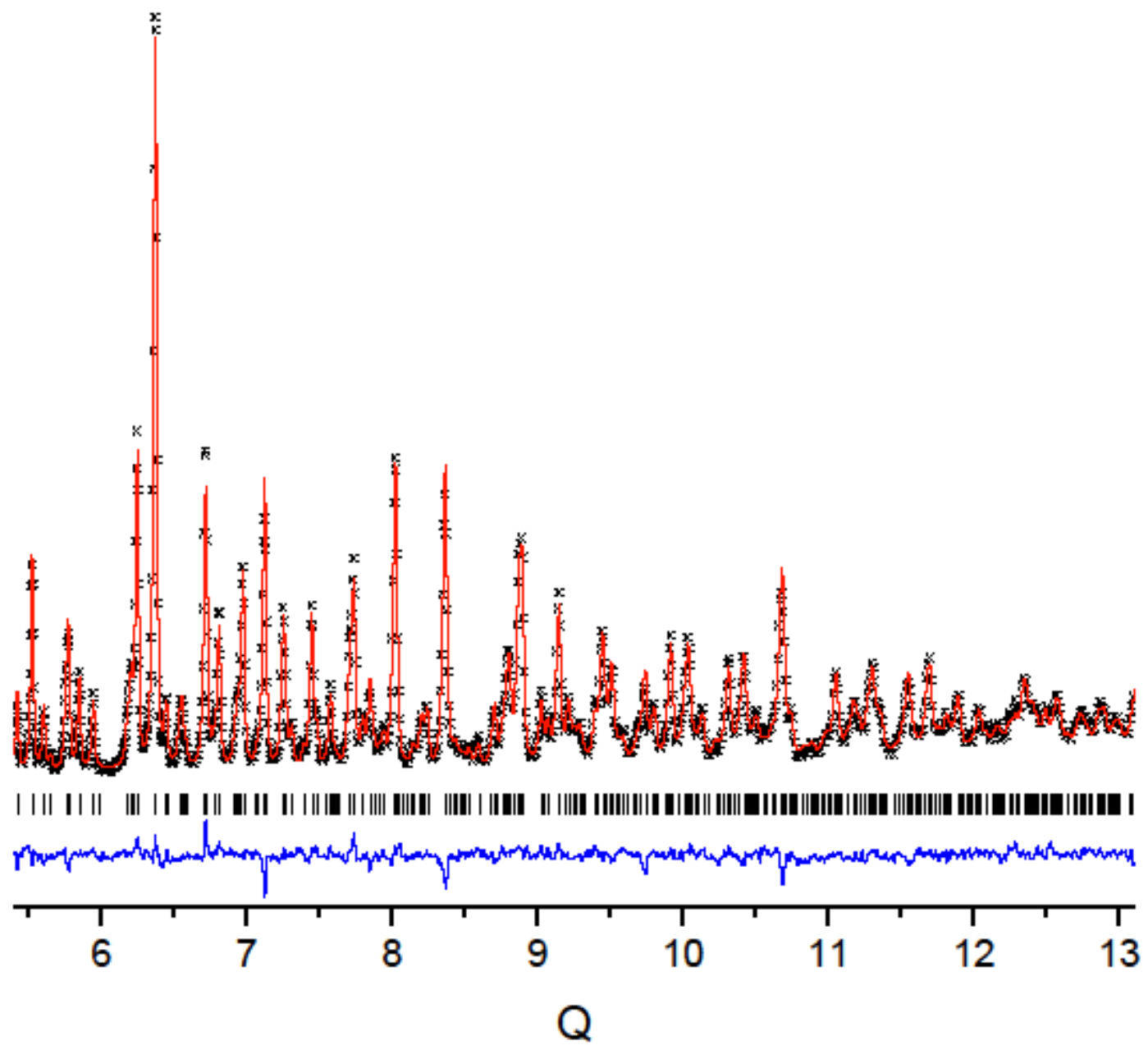


Figure S3: Rietveld refinement of S-XRD of $\left(\mathrm{Mg}_{0.59}^{2+} \mathrm{Mn}_{0.41}^{2+}\right)\left[\left(\mathrm{Mg}_{0.41}^{2+} \mathrm{Mn}_{1.18}^{3+} \mathrm{Mn}_{0.41}^{4+}\right] \mathrm{O}_{4}\right.$

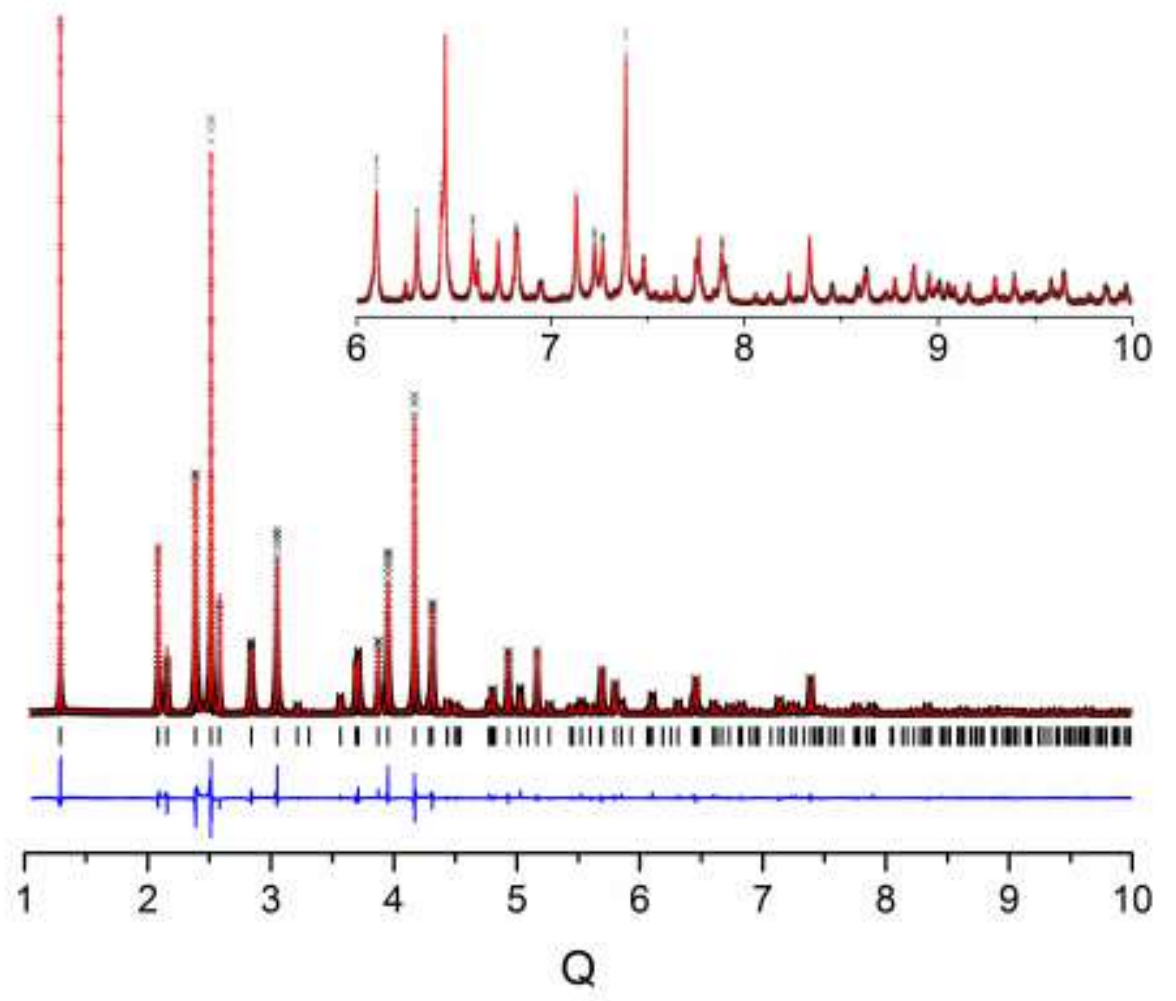


Figure S4: Rietveld refinement of TOF-NPD of $\left(\mathrm{Mg}_{0.59}^{2+} \mathrm{Mn}_{0.41}^{2+}\right)\left[\left(\mathrm{Mg}_{0.41}^{2+} \mathrm{Mn}_{1.18}^{3+} \mathrm{Mn}_{0.41}^{4+}\right] \mathrm{O}_{4}\right.$

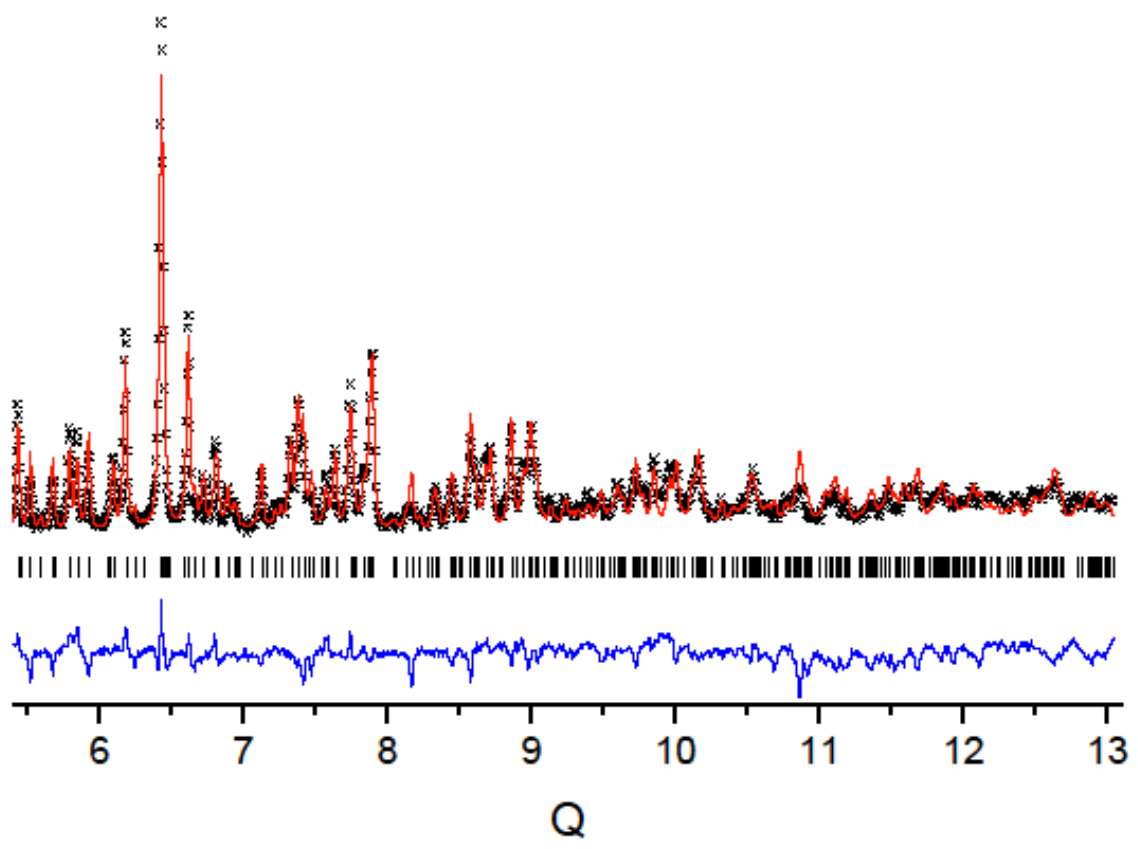


Figure S5: G(r) TOF-NPD of $\mathrm{Mg}[\mathrm{Mn}]_{2} \mathrm{O}_{4}$ and comparison with the model arising from Rietveld refinements above.

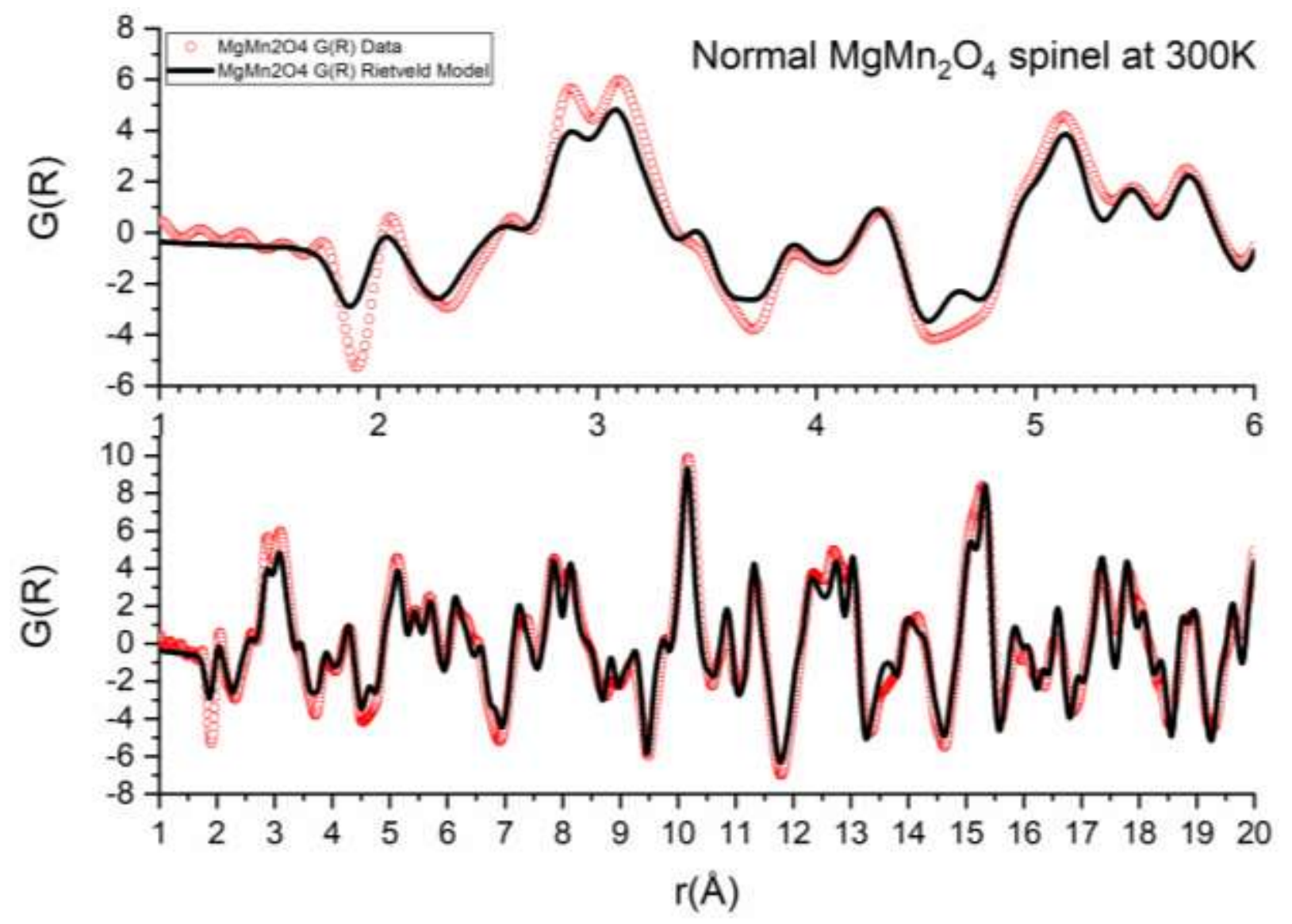


Figure S6: $\mathrm{G}(\mathrm{r})$ TOF-NPD of $\left(\mathrm{Mg}_{0.59}^{2+} \mathrm{Mn}_{0.41}^{2+}\right)\left[\left(\mathrm{Mg}_{0.41}^{2+} \mathrm{Mn}_{1.18}^{3+} \mathrm{Mn}_{0.41}^{4+}\right] \mathrm{O}_{4}\right.$ and comparison with the model arising from Rietveld refinements above.

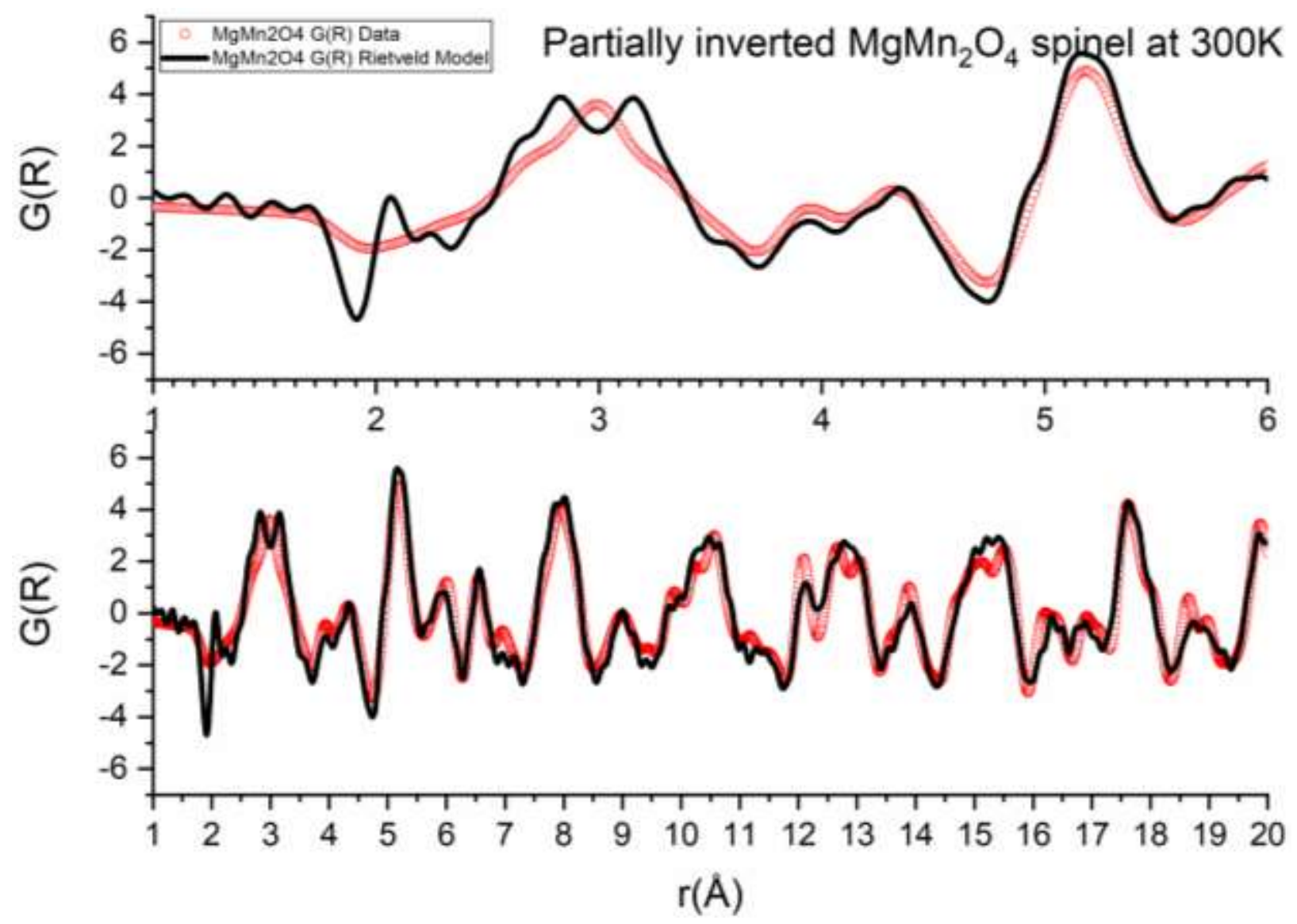


Figure S7: Rietveld refinement of $\mathrm{Mg}_{1.15} \mathrm{Cr}_{1.85} \mathrm{O}_{4}$ and 8.1 wt $\% \mathrm{Cr}_{2} \mathrm{O}_{3}$

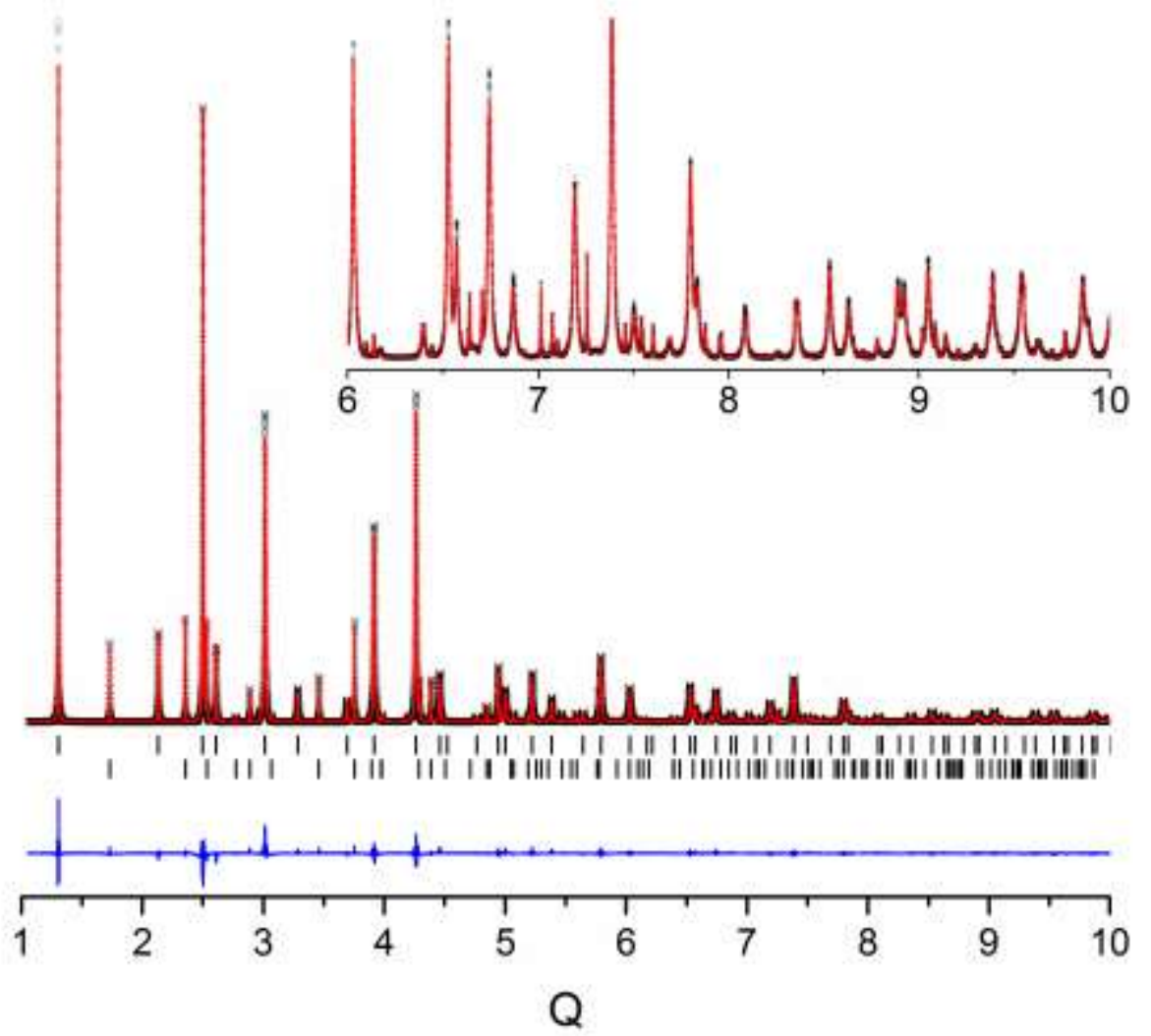


Table S1: Summary of results of the joint Rietveld Refinement of Normal $(\mathrm{Mg})[\mathrm{Mn}]_{2} \mathrm{O}_{4}$

\begin{tabular}{|l||l||}
\hline Formula & $\mathrm{MgMn}_{2} \mathrm{O}_{4}$ \\
\hline \hline$a(\AA)$ & $5.72384(1)$ \\
$\mathrm{c}(\AA)$ & $9.26302(3)$ \\
\hline \hline$V\left(\AA^{3}\right)$ & $303.478(1)$ \\
\hline \hline Space group & I4 $/$ amd \\
\hline \hline Number of parameters refined & 46 \\
\hline \hline -ray $R_{w p}$ & $8.87 \%$ \\
$X$-ray $R_{p}$ & $7.02 \%$ \\
\hline \hline$N P D R_{w p}$ & $7.15 \%$ \\
$N P D R_{p}$ & $5.49 \%$ \\
\hline
\end{tabular}


Table S2: Summary of results of the joint Rietveld Refinement of Inverted $\left(\mathrm{Mn}_{0.41} \mathrm{Mg}_{0.59}\right)\left[\mathrm{Mn}_{1.59} \mathrm{Mg}_{0.41}\right] \mathrm{O}_{4}$

\begin{tabular}{|l||l|}
\hline Formula & \multicolumn{1}{|c|}{$\left(\mathrm{Mg}_{0.59}^{2+} \mathrm{Mn}_{0.41}^{2+}\right)\left[\left(\mathrm{Mg}_{0.41}^{2+} \mathrm{Mn}_{1.18}^{3+} \mathrm{Mn}_{0.41}^{4+}\right] \mathrm{O}_{4}\right.$} \\
\hline $\begin{array}{l}a(\AA) \\
\mathrm{c}(\AA)\end{array}$ & $5.82641(2)$ \\
\hline \hline$V\left(\AA^{3}\right)$ & $300.34758(2)$ \\
\hline \hline Space group & $I 4{ }_{1} /$ amd \\
\hline Number of parameters refined & 41 \\
\hline$X$-ray $R_{w p}$ & $10.48 \%$ \\
$X$-ray $R_{p}$ & $8.34 \%$ \\
\hline NPD $R_{w p}$ & $9.16 \%$ \\
$N P D R_{p}$ & $6.79 \%$ \\
\hline
\end{tabular}


Table S3: Summary of results of the joint Rietveld Refinement of $\mathrm{Mg}_{1.15} \mathrm{Cr}_{1.85} \mathrm{O}_{4}$ and $\mathrm{Cr}_{2} \mathrm{O}_{3}$ impurity

\begin{tabular}{|l||l||}
\hline Formula & $\mathrm{Mg}_{1.15} \mathrm{Cr}_{1.85} \mathrm{O}_{4}$ \\
\hline \hline$a(\AA)$ & $8.33466(2)$ \\
\hline \hline$V\left(\AA^{3}\right)$ & $578.980(3)$ \\
\hline \hline Space group & $F d-3 m$ \\
\hline \hline Number of parameters refined & 59 \\
\hline \hline $\begin{array}{l}\text {-ray } R_{w p} \\
X-\text { ray } R_{p}\end{array}$ & $8.74 \%$ \\
$6.53 \%$ \\
\hline
\end{tabular}

\begin{tabular}{|l||l||}
\hline Formula & $\mathrm{Cr}_{2} \mathrm{O}_{3}$ Impurity $(8.1 \mathrm{wt} \%)$ \\
\hline \hline$a(\AA)$ & $\begin{array}{l}4.95897(1) \\
13.56557(5)\end{array}$ \\
\hline \hline$V(\AA)$ & $289.542(2)$ \\
\hline \hline Space group & $R-3 c$ \\
\hline
\end{tabular}




\section{Analysis of Linewidths by Variable Temperature Solid State NMR}

The narrowing of the central resonance of $\mathrm{Mg}_{1.15} \mathrm{Cr}_{1.85} \mathrm{O}_{4}$ with temperature was fit according to the ad hoc formalism for motional averaging shown in Equation 1, where $\delta_{0}$ and $\delta_{\infty}$ denotes the linewidth below and above the onset temperature respectively, where $\varsigma$ is a fit parameter here chosen to be one, $\mathrm{k}_{\mathrm{B}}$ denotes Boltzmann's constant and $\tau_{0}{ }^{\mathrm{MN}}$ represents the preexponential factor of the corresponding correlation time $\tau_{c}{ }^{\mathrm{MN}}$ leading to $E_{a}{ }^{M N}$ for motional narrowing (MN) of $510 \pm 190$ $\mathrm{meV}$ with a pre-exponential factor of $2.2 \times 10^{-9} \mathrm{~s}$ suggesting remarkably facile ion dynamics for $\mathrm{Mg}_{1.15} \mathrm{Cr}_{1.85} \mathrm{O}_{4}$.

$$
\delta(T)=\sqrt{\delta_{0}^{2} \frac{2}{\pi} \arctan \left[\varsigma \delta(T) \tau_{0} M N \exp \left(\frac{E_{a}^{M N}}{k_{B} T}\right)\right]+\delta_{\infty}^{2}}
$$

This value was used to calibrate the analysis of correlation times, $\tau_{\mathfrak{c}}$, for $\mathrm{MgMn}_{2} \mathrm{O}_{4}$, where clear onsets in line narrowing were not observed. Motional narrowing of the NMR resonance takes place when the rate of fluctuations of the local magnetic and/or electric fields is high. These fluctuations are generally described by a correlation time $\tau_{\mathrm{c}}$ in Equations 2, in the rigid lattice regime below $250 \mathrm{~K}$ (Figure 2e), and $\mathbf{3}$, defined by the Bloembergen-Purcell-Pound (BPP) theory. In both cases, $\delta \omega_{\mathrm{o}}$ is the measured linewidth in frequency (FWHM) at a given temperature. The temperature dependence of the $\tau_{\mathrm{c}}$ in Figure $2 \mathrm{f}$ follows an Arrhenius relationship, as in Equation 4. Using the bare Equation 4 (sans $\alpha$ term) resulted in unrealistically low activation energies due to the presence of paramagnetic centers in the samples, a phenomenon that has been observed to alter measured activation barriers previously. The slopes within the experimental temperature are inversely correlated with relative mobilities of the samples, showing a clear trend of relative decrease in migration rates from $\mathrm{Cr}$ to $\mathrm{Mn}$ to inverse $\mathrm{Mn}$ spinel. It was assumed that a direct semiquantitative comparison was still possible provided that all three spinels shared similar paramagnetic signatures based on the overlap of observed NMR shifts, similar local $\mathrm{Mg}$ coordinations and lattices. Thus, a pre-factor $(\alpha)$ with an actual value of 2.681 is applied to the calculated activation energy derived from correlation times in Equation 4 to obtain the value of $510 \mathrm{meV}$ which was extracted using Equation 1. The determined pre-factor $(\alpha)$ was then applied universally for the fits of Mn-compounds in Figure 3e. This led to an activation energy, $E_{a}=690$ $\pm 90 \mathrm{meV}$, for $\mathrm{Mg}^{2+}$ hopping within normal $\mathrm{MgMn}_{2} \mathrm{O}_{4}$ (Figure 2f) fully adhering to BPP theory for the normal spinels with accurate estimations of linewidths. In the case of inverted $\left(\mathrm{Mg}_{0.59} \mathrm{Mn}_{0.41}\right)\left[\mathrm{Mg}_{0.41} \mathrm{Mn}_{1.59}\right] \mathrm{O}_{4}$, employing a similar analysis, using the same pre-factor obtained from $\mathrm{Mg}_{1.15} \mathrm{Cr}_{1.85} \mathrm{O}_{4}$, led to an activation energy of $1100 \pm 140 \mathrm{meV}$ from ssNMR. The number obtained for this inverted spinel is, thus, significantly lower than the theoretical prediction, which is a reflection of the semi-quantitative nature of this analysis and the magnitude of unquantifiable errors in determining reliable linewidths. These errors originate from magnetic and paramagnetic effects, as well as limitations of the BPP theory to estimate activation energies. Nonetheless, this analysis still supports the notion that activation barriers for hopping are higher in inverted than normal spinels in a significant manner. 
$1 / \tau_{c} \cong \delta \omega_{0}$

$(\Delta v)^{2}=\left(\frac{2}{\pi}\right) \delta \omega_{0}^{2} \tan ^{-1}\left(\tau_{c} \Delta v\right)$

$\ln \tau_{c}=\alpha \frac{E_{a}}{k T}+\ln \tau_{0}$

Figure S8: ${ }^{25} \mathrm{Mg}$ MAS NMR spectrum of inverted $\left(\mathrm{Mn}_{0.41} \mathrm{Mg}_{0.59}\right)\left[\mathrm{Mn}_{1.59} \mathrm{Mg}_{0.41}\right] \mathrm{O}_{4}$, normal $\mathrm{MgMn}_{2} \mathrm{O}_{4}$ and normal $\mathrm{Mg}_{1.15} \mathrm{Cr}_{1.85} \mathrm{O}_{4}$ (" $\mathrm{MgCr}_{2} \mathrm{O}_{4}$ ") collected at 19.89 Tesla with $15 \mathrm{kHz}$ and $10 \mathrm{kHz}$ spinning speed, respectively (11.7 Tesla for partially inverted sample, $20 \mathrm{kHz}$ spinning speed)

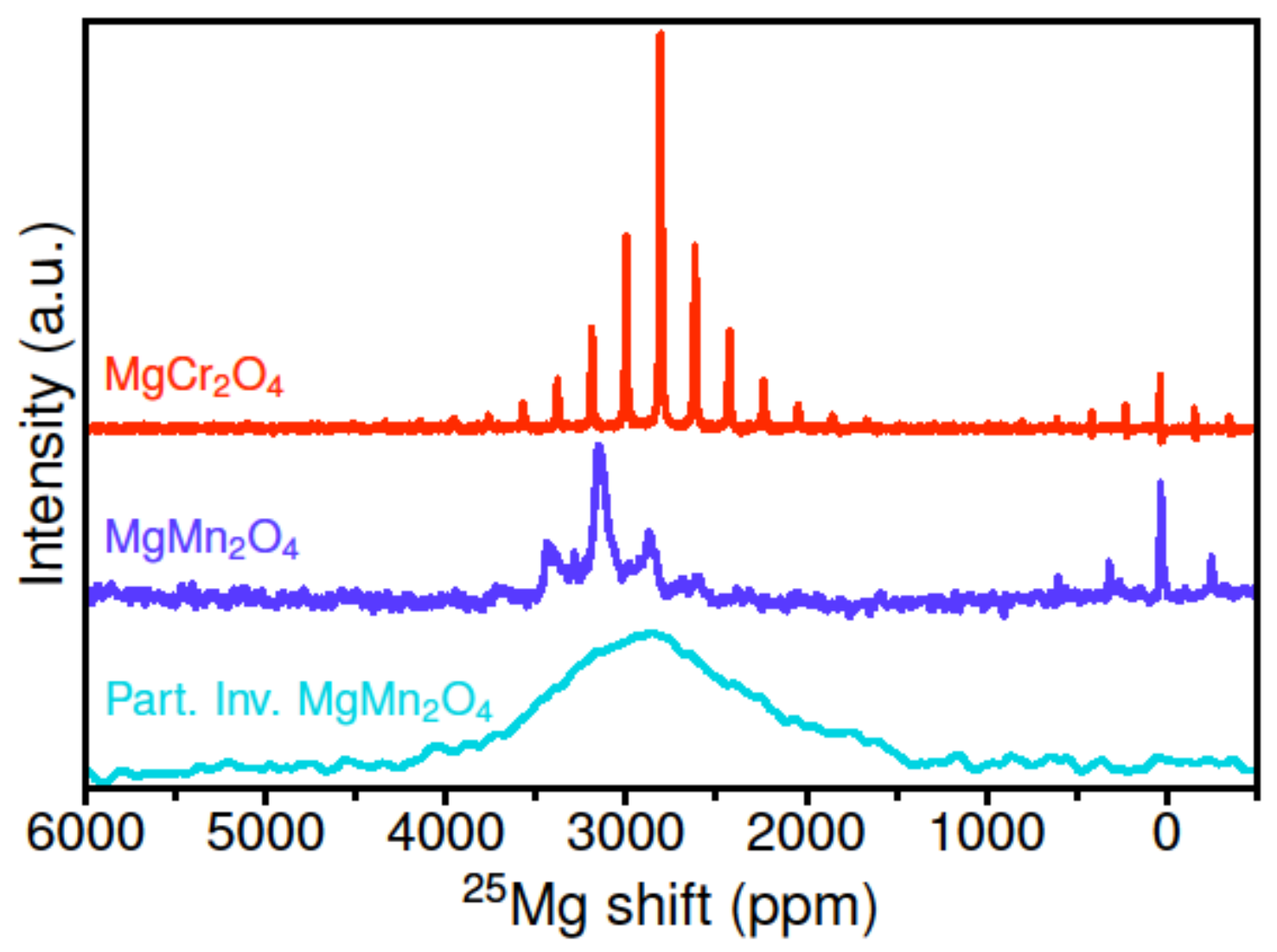


Figure S9: Quadrupolar fitting of NMR data of $\mathrm{Mg}_{1.15} \mathrm{Cr}_{1.85} \mathrm{O}_{4}$ collected at $333 \mathrm{~K}$. Two site fit is shown for the main $\mathrm{Mg}_{\text {tet }}$ and the minor $\mathrm{Mg}_{\text {oct }}$ sites (assignments based on complementary characterization data), at higher temperatures near-complete site mixing observed within NMR timescales (See Figure S29).

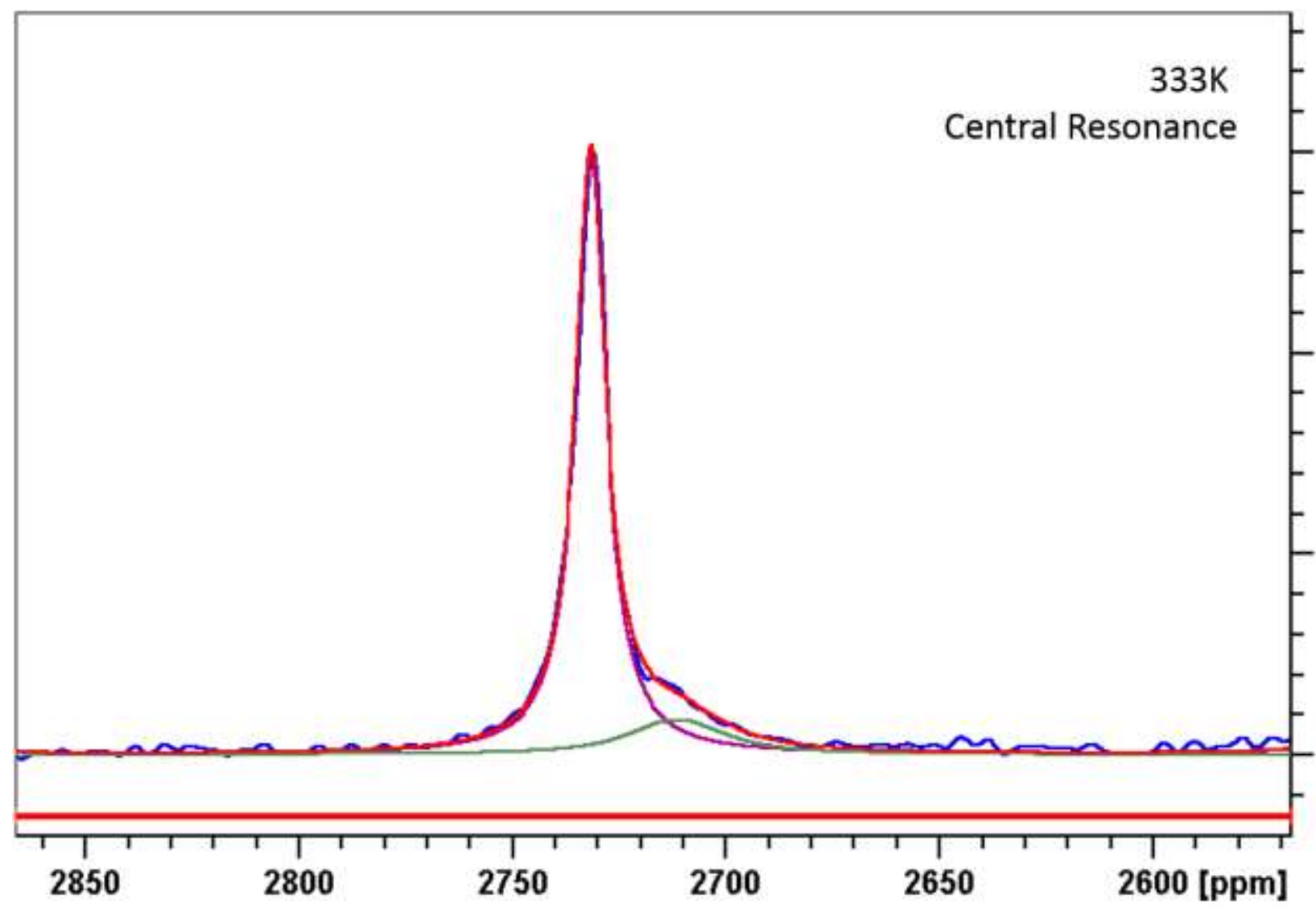


Figure S10: VT ${ }^{25} \mathrm{Mg}$ MAS NMR of $\mathrm{Mg}_{1.15} \mathrm{Cr}_{1.85} \mathrm{O}_{4}$ collected at 19.89 Tesla

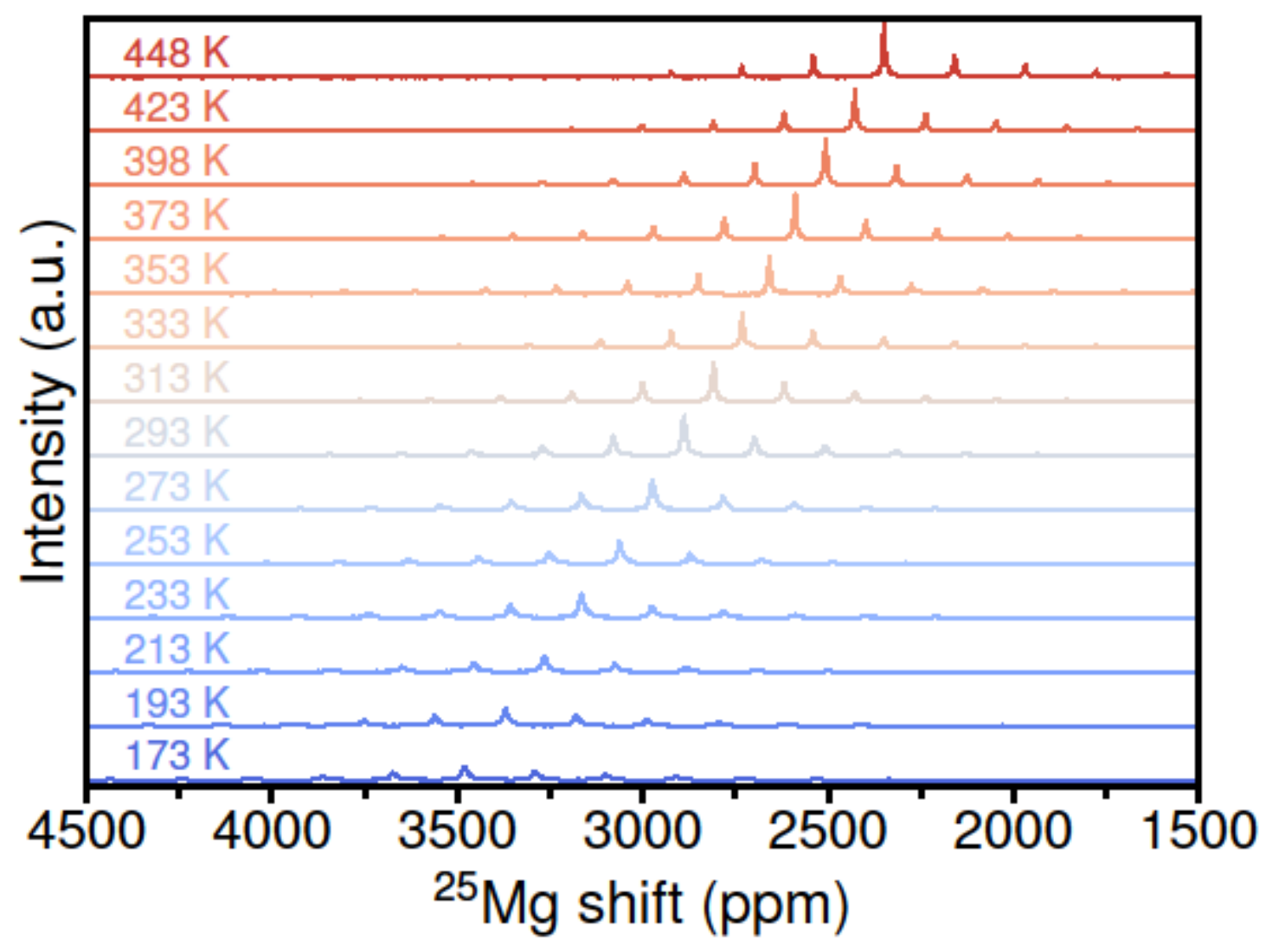


Figure S11: VT ${ }^{25} \mathrm{Mg}$ MAS NMR of normal $\mathrm{MgMn}_{2} \mathrm{O}_{4}$ collected at 11.7 Tesla

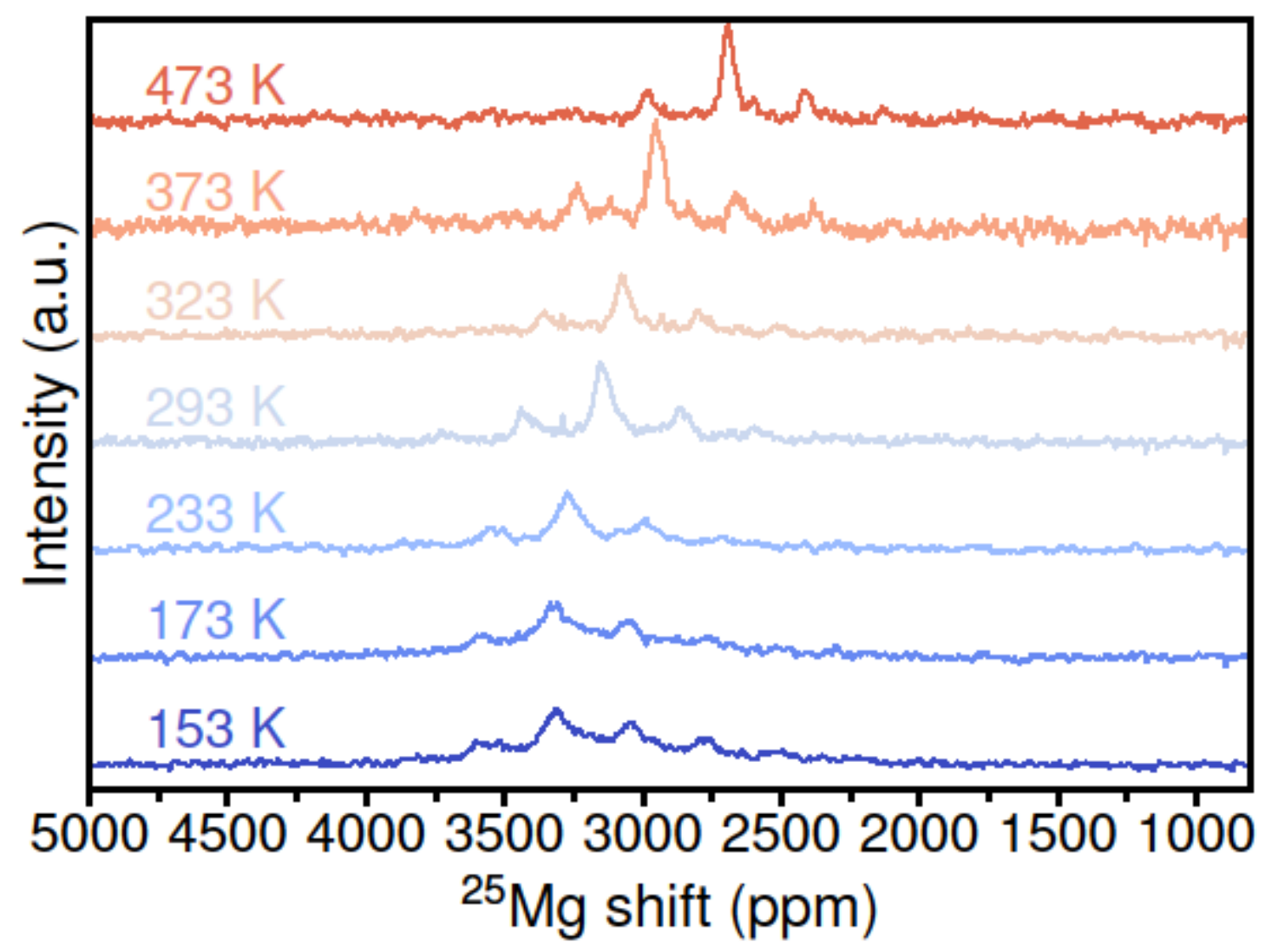


Figure S12: Quadrupolar fitting of representative variable temperature NMR data of $\mathrm{Mg}_{1.15} \mathrm{Cr}_{1.85} \mathrm{O}_{4}$.

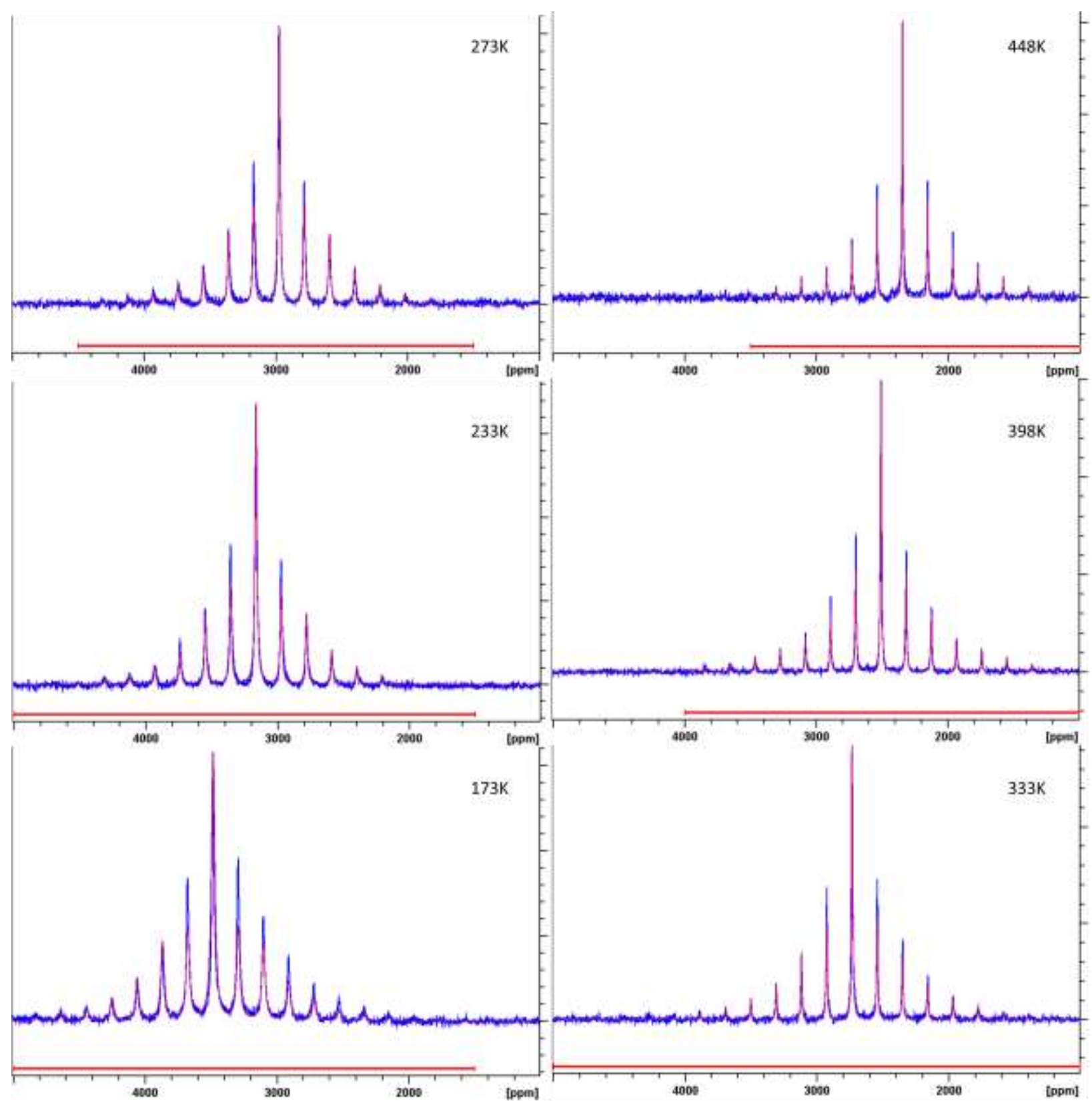


Figure S13: Temperature dependence of the NMR peak position of $\mathrm{Mg}_{1.15} \mathrm{Cr}_{1.85} \mathrm{O}_{4}$. The non-linear behavior is ascribed to possible magnetic effects.

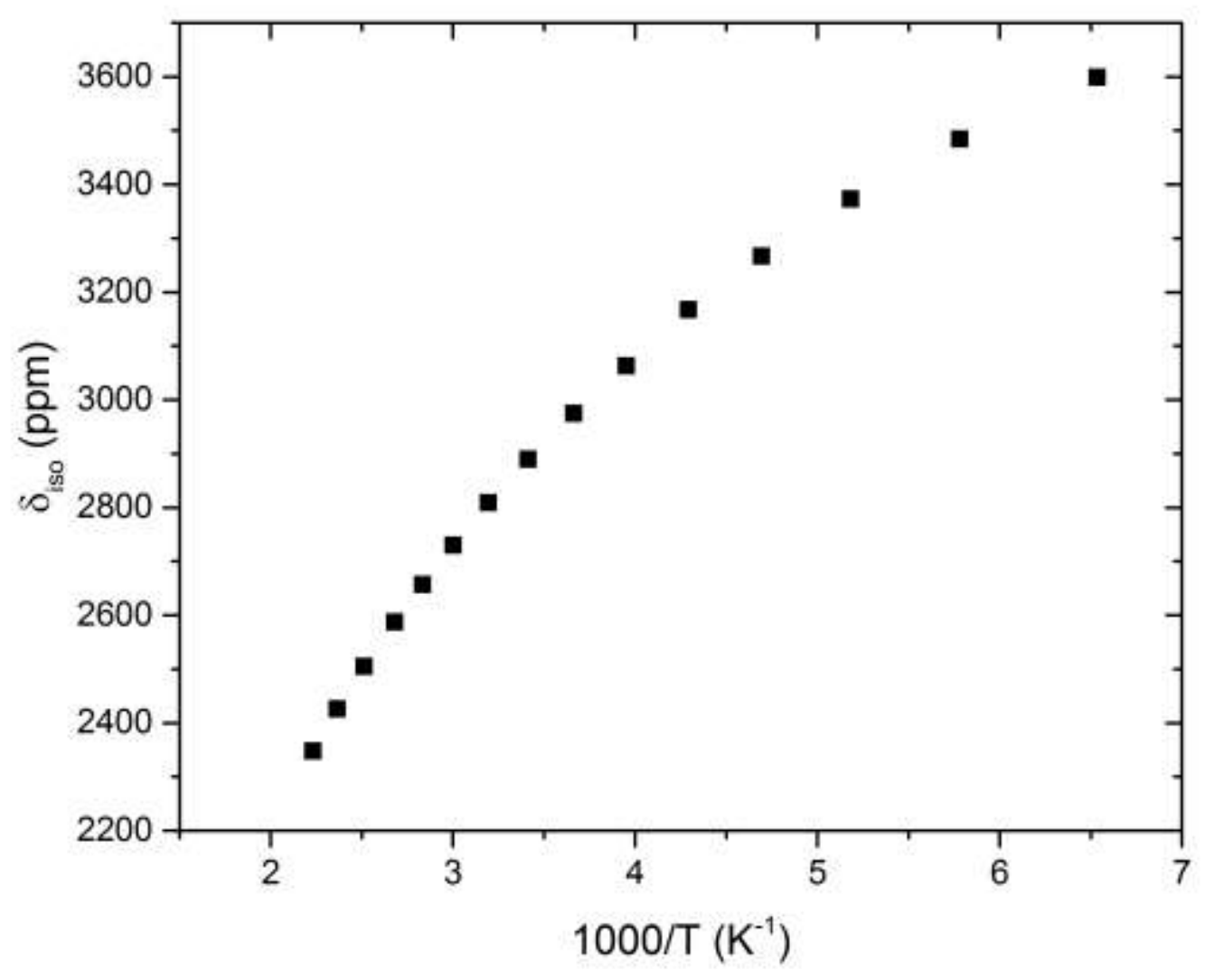


Figure S14: Temperature dependence of the fitted NMR asymmetry parameter of $\mathrm{Mg}_{1.15} \mathrm{Cr}_{1.85} \mathrm{O}_{4}$. The quadrupolar coupling constant, $\mathrm{C}_{\mathrm{Q}}$, was found to be $240 \pm 30 \mathrm{kHz}$

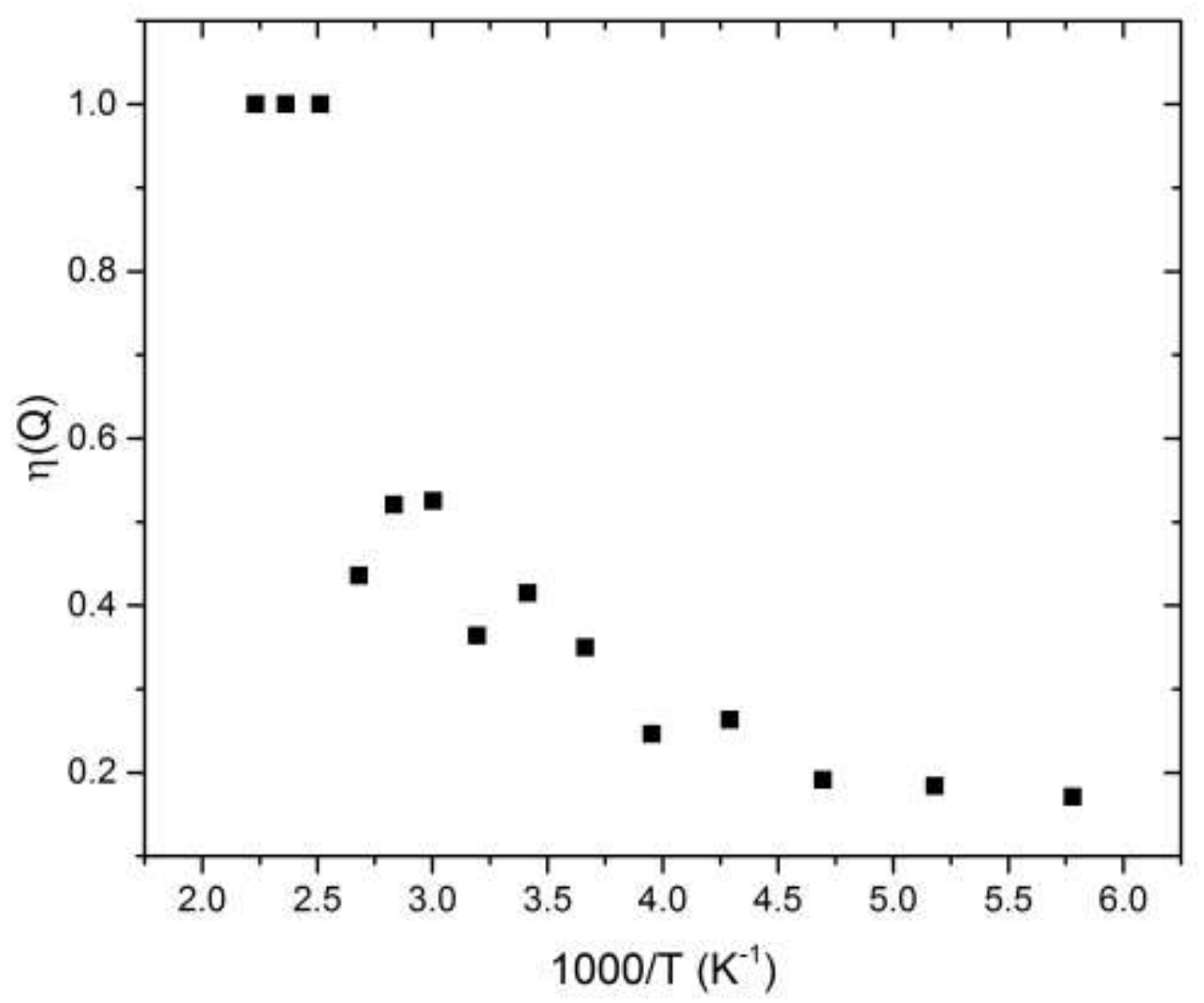


Figure S15: Quadrupolar fitting of representative variable temperature NMR data of normal $\mathrm{MgMn}_{2} \mathrm{O}_{4}$

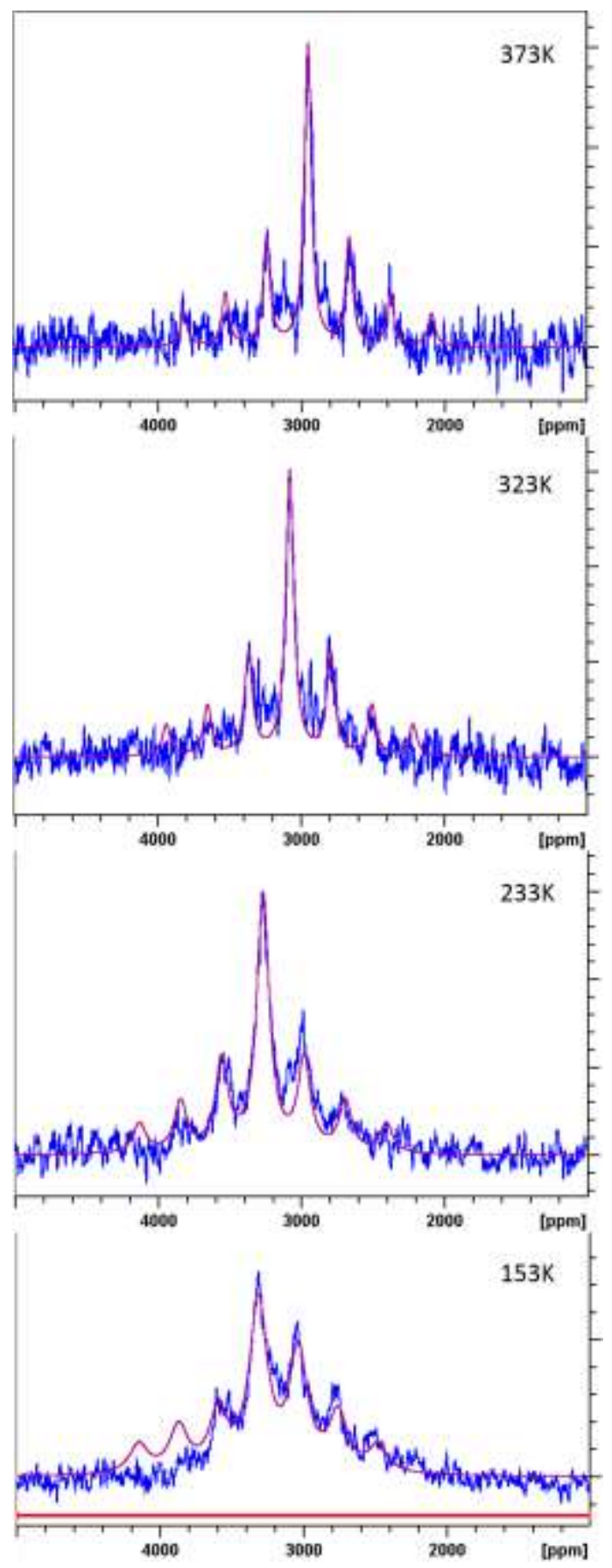


Figure S16: Temperature dependence of the NMR peak position of normal $\mathrm{MgMn}_{2} \mathrm{O}_{4}$. The nonlinear behavior is ascribed to magnetic effects originating from manganese.

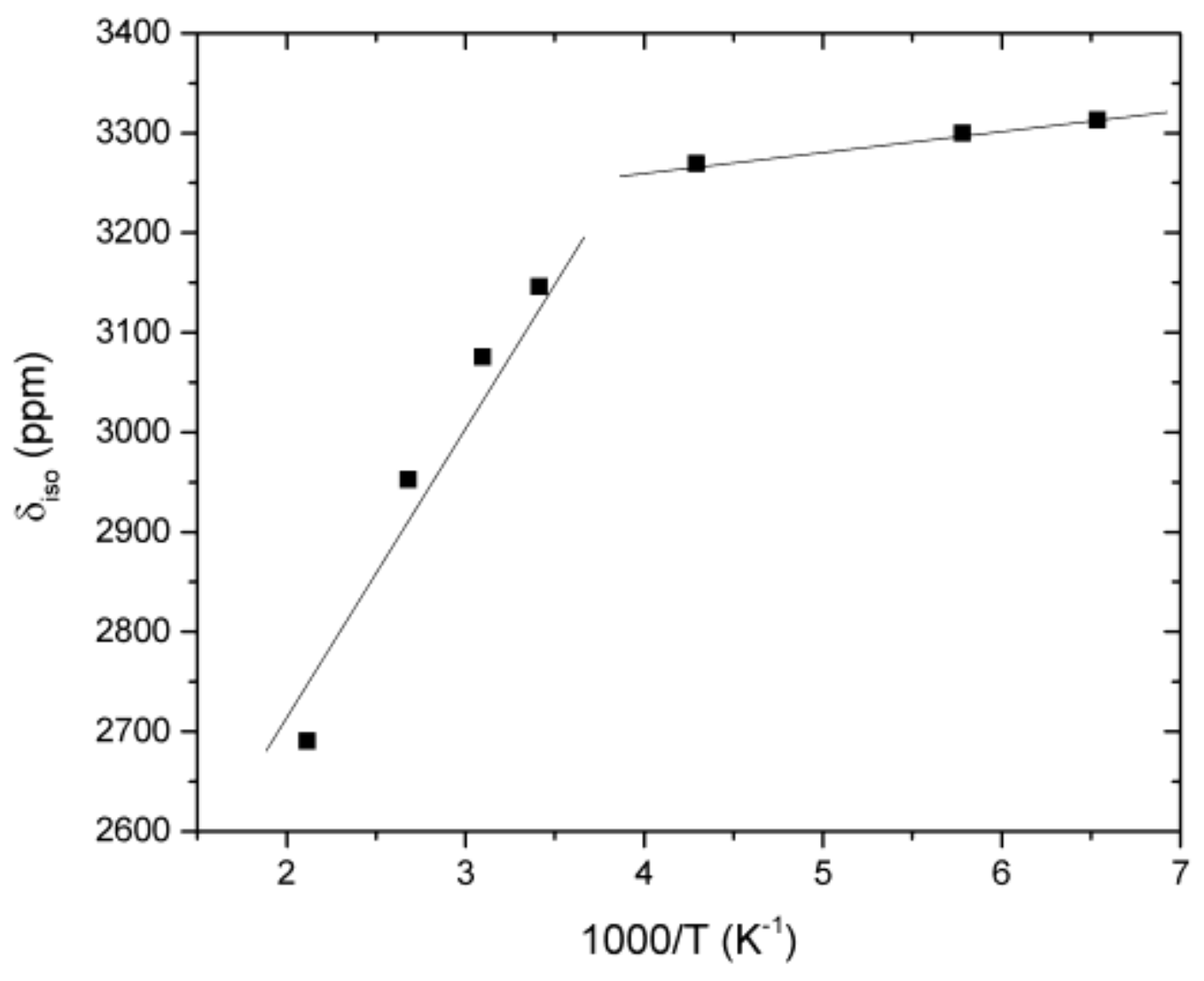


Figure S17: Temperature dependence of the NMR quadrupolar coupling constant, $\mathrm{C}_{\mathrm{Q}}$, of normal $\mathrm{MgMn}_{2} \mathrm{O}_{4}$.

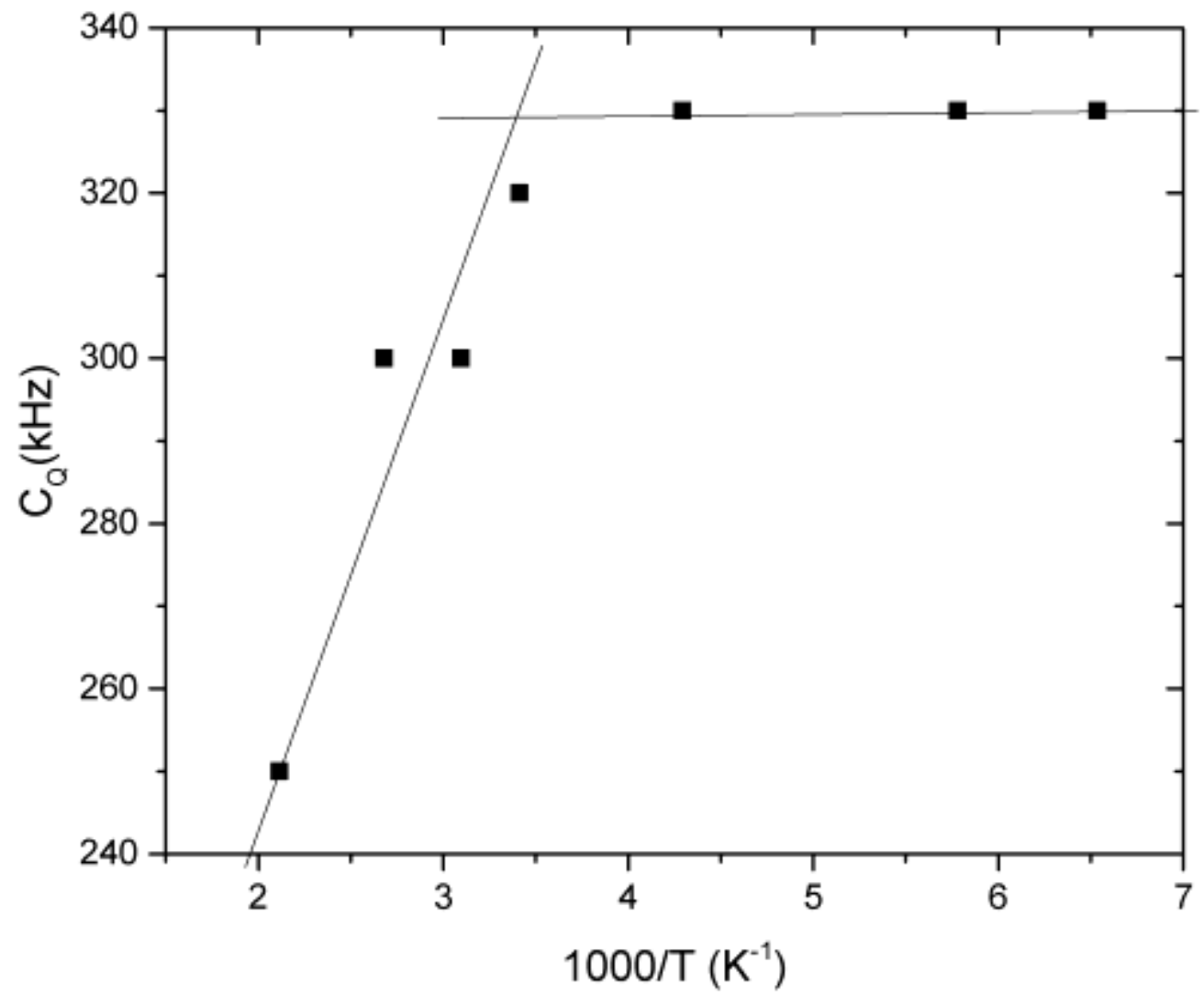


Figure S18: Comparison of the temperature dependence of the NMR peak width of spinels $\mathrm{Mg}_{1.15} \mathrm{Cr}_{1.85} \mathrm{O}_{4}$ and $\mathrm{LiMn}_{2} \mathrm{O}_{4}$, suggestive of spinel cationic dynamics in analogy to the $\mathrm{Li}$-ion counterparts.

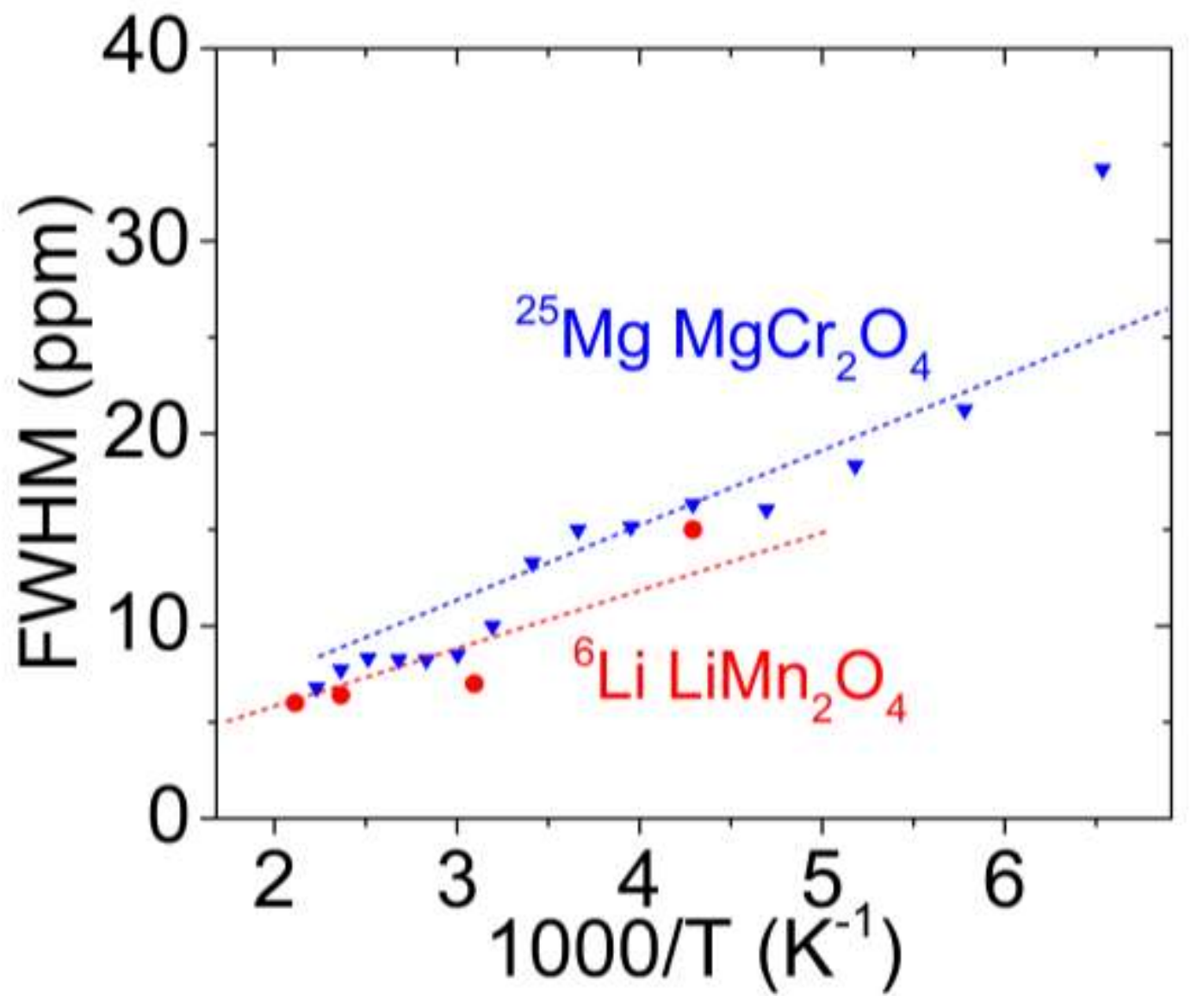


Figure S19: Temperature dependence of the linewidth of the full NMR signal envelope, $\delta \omega_{0}$, of $\mathrm{Mg}_{1.15} \mathrm{Cr}_{1.85} \mathrm{O}_{4}$. Black points indicate experimental data, whereas the red line indicates the fit using equation 1 . The fit revealed $T_{c}=235 \mathrm{~K}$, which leads to an empirical value of activation energy for motional narrowing from the Waugh and Fedin model, $\mathrm{E}_{\mathrm{a}}^{\mathrm{MN}, \mathrm{WF}}=1.617 \cdot \mathrm{T}_{\mathrm{c}}=380 \pm 290 \mathrm{meV}$.

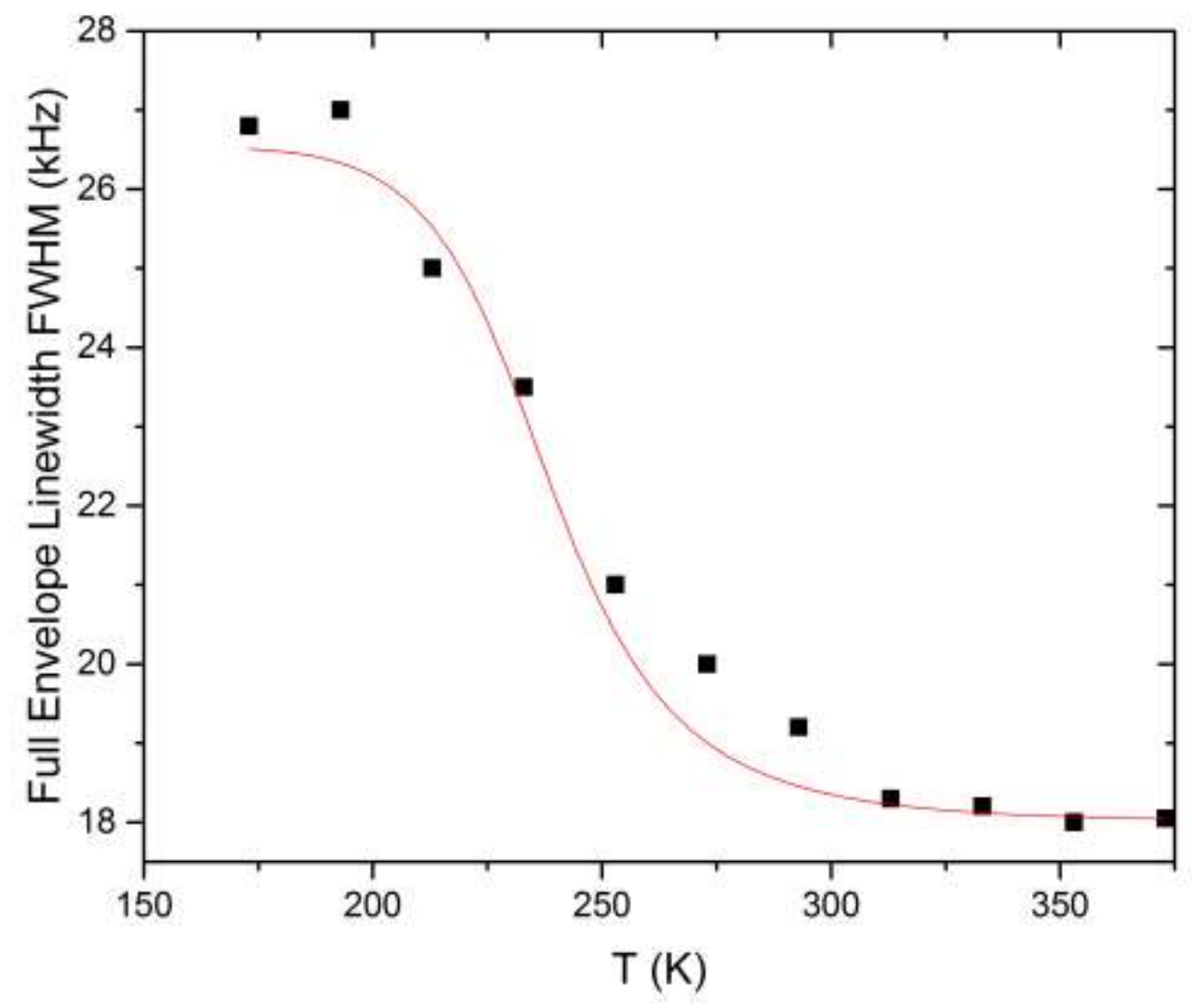


Figure S20: Raw muon decay asymmetry data from the normal $\mathrm{MgMn}_{2} \mathrm{O}_{4}$ spinel at a) $200 \mathrm{~K}$ and b) $400 \mathrm{~K}$, in zero field and magnetic fields of 5 and $10 \mathrm{G}$ applied along the initial muon spin direction. The fitted lines are to the damped dynamic Gaussian Kubo-Toyabe function described in the text. The change between datasets is consistent with the change in the applied field. The difference between the two temperatures is explained by the changing dynamics due to $\mathrm{Mg}$ motion
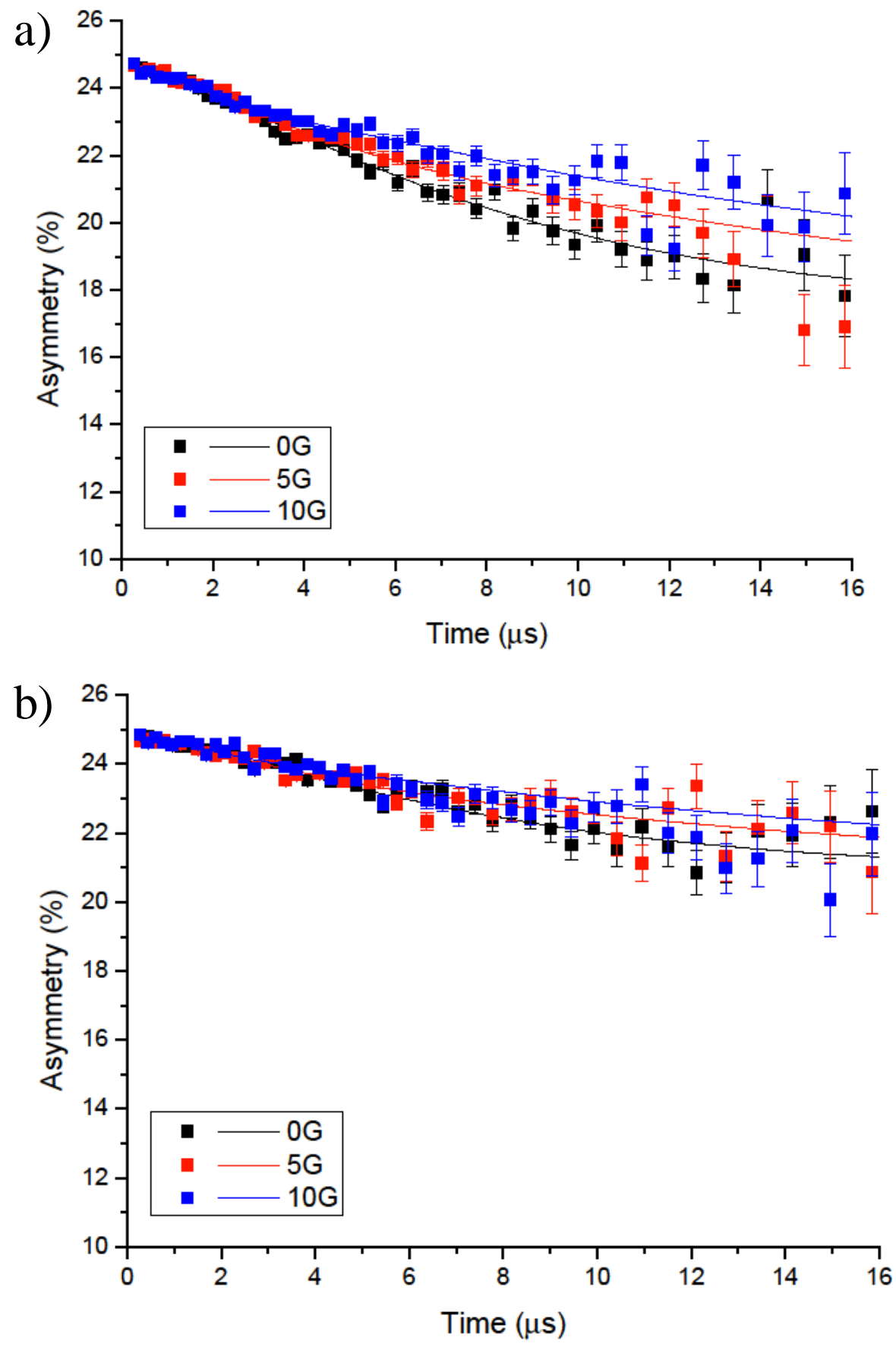
Figure S21: Contributions to the muon decay asymmetry in the normal $\mathrm{MgMn}_{2} \mathrm{O}_{4}$ spinel: Initial $=\mathrm{A}(\mathrm{t}=0)$, Baseline $=\mathrm{A}(\mathrm{t} \rightarrow \infty)$, Relaxing $=$ Initial - Baseline

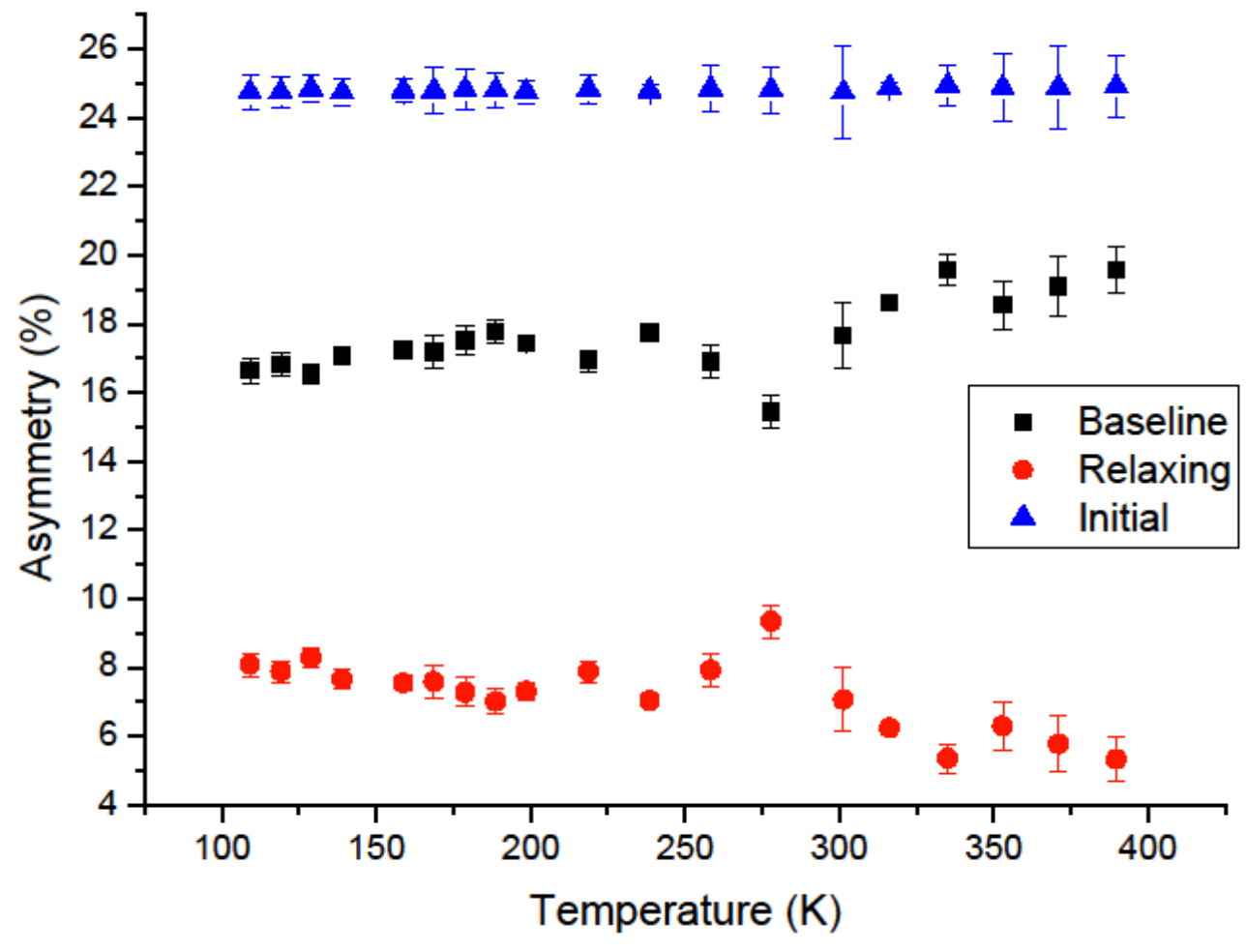


Figure S22: Distribution width of nuclear magnetic fields $\Delta$ from fits to the raw data of the normal $\mathrm{MgMn}_{2} \mathrm{O}_{4}$ spinel

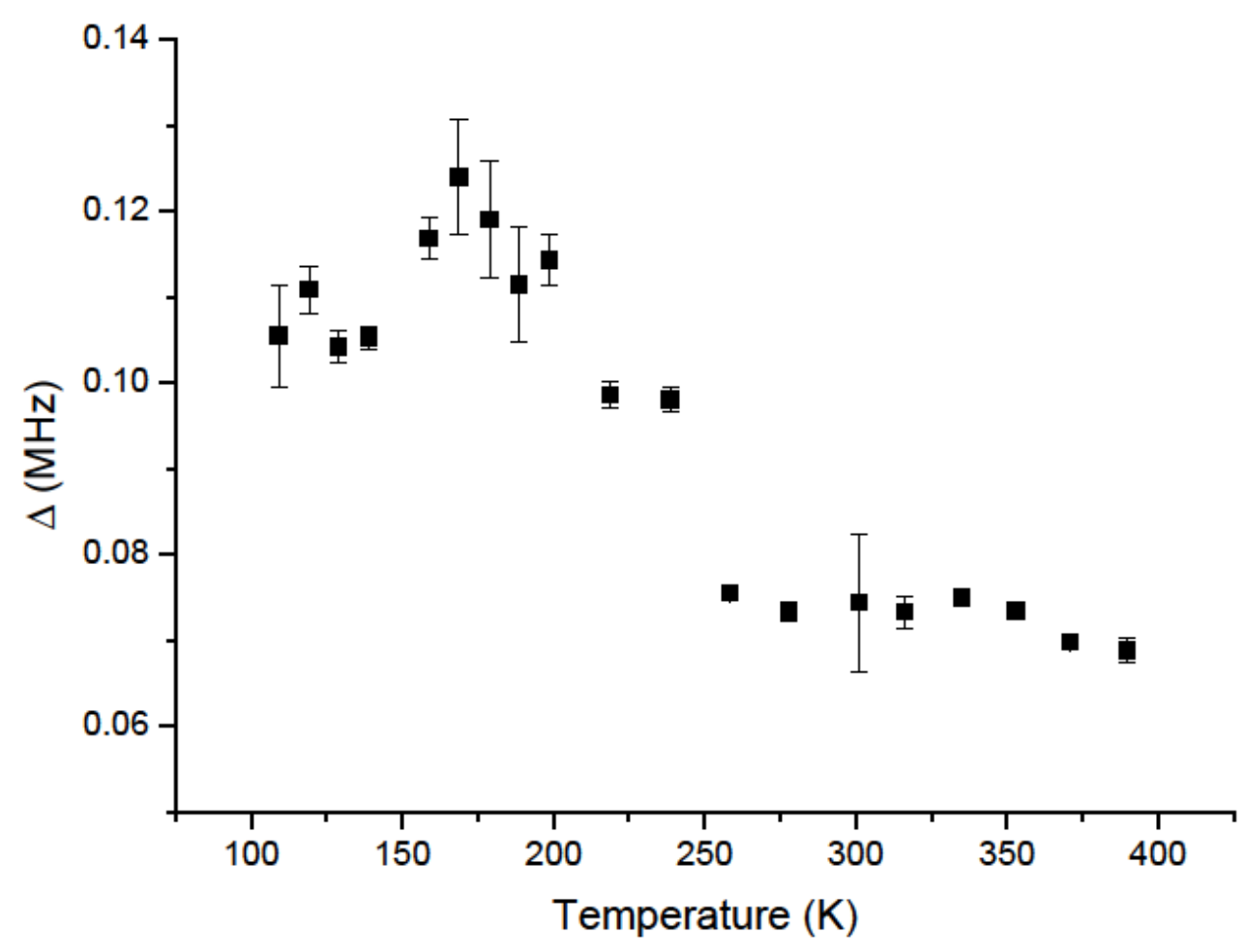


Figure S23: Damping rate $\lambda$ due to paramagnetic fluctuations in the normal $\mathrm{MgMn}_{2} \mathrm{O}_{4} \mathrm{Sample}$

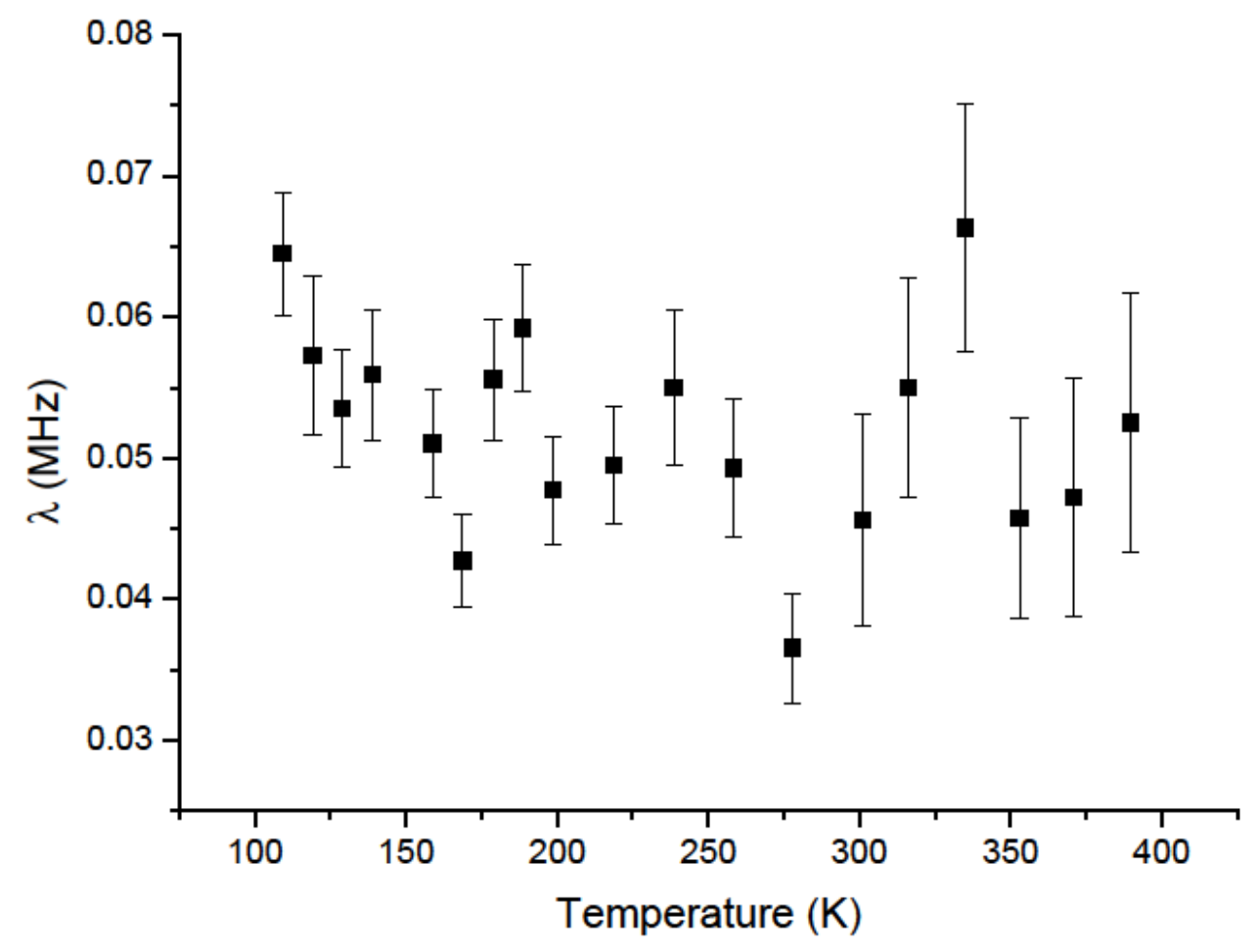


Figure S24: Raw muon decay asymmetry data from the normal $\mathrm{MgCr}_{2} \mathrm{O}_{4}$ spinel at $300 \mathrm{~K}$ in zero field and magnetic fields of 5 and $10 \mathrm{G}$ applied along the initial muon spin direction. The fitted lines are to the damped dynamic Gaussian Kubo-Toyabe function described in the text. In these conditions, dynamics reduce the effect of the decoupling field, comparable with S20b,

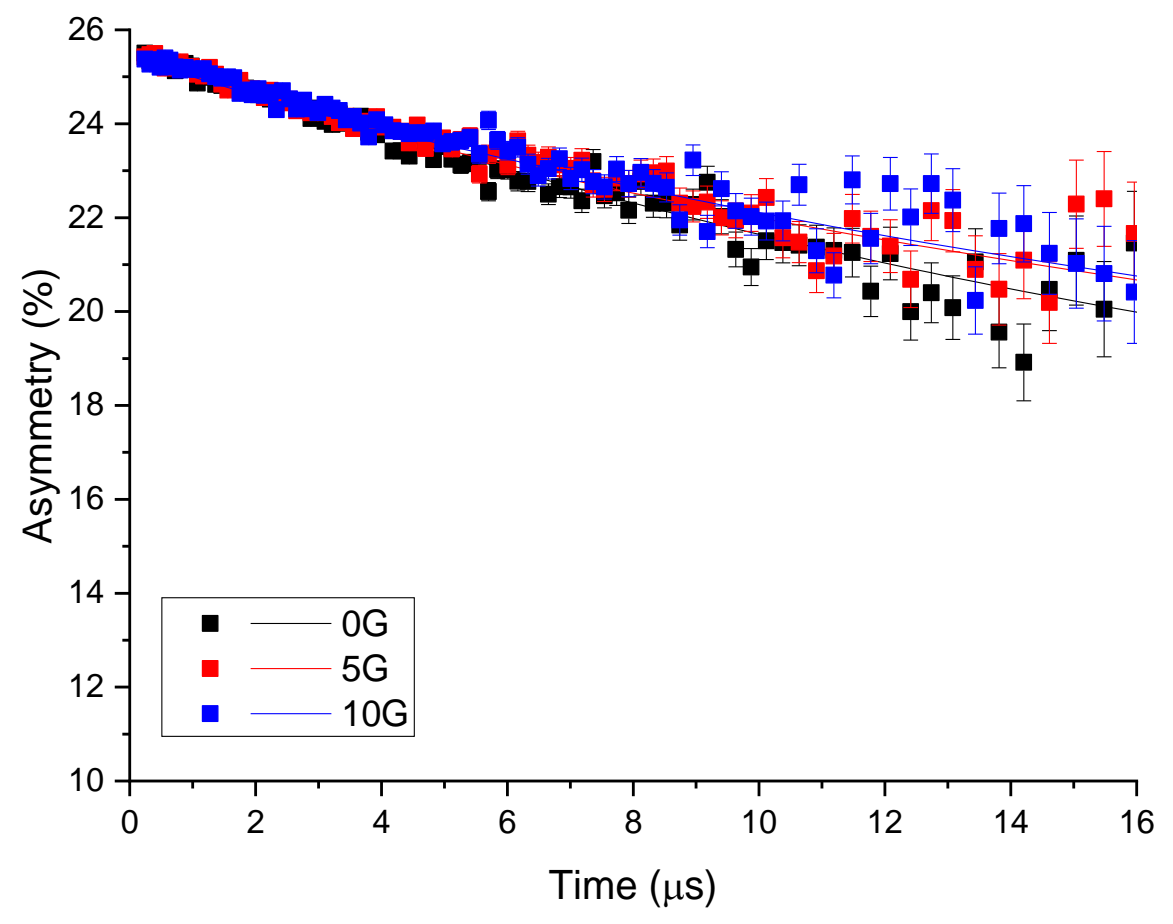


Figure S25: Distribution width of nuclear magnetic fields $\Delta$ from fits to the raw data of the normal $\mathrm{MgCr}_{2} \mathrm{O}_{4}$ spinel

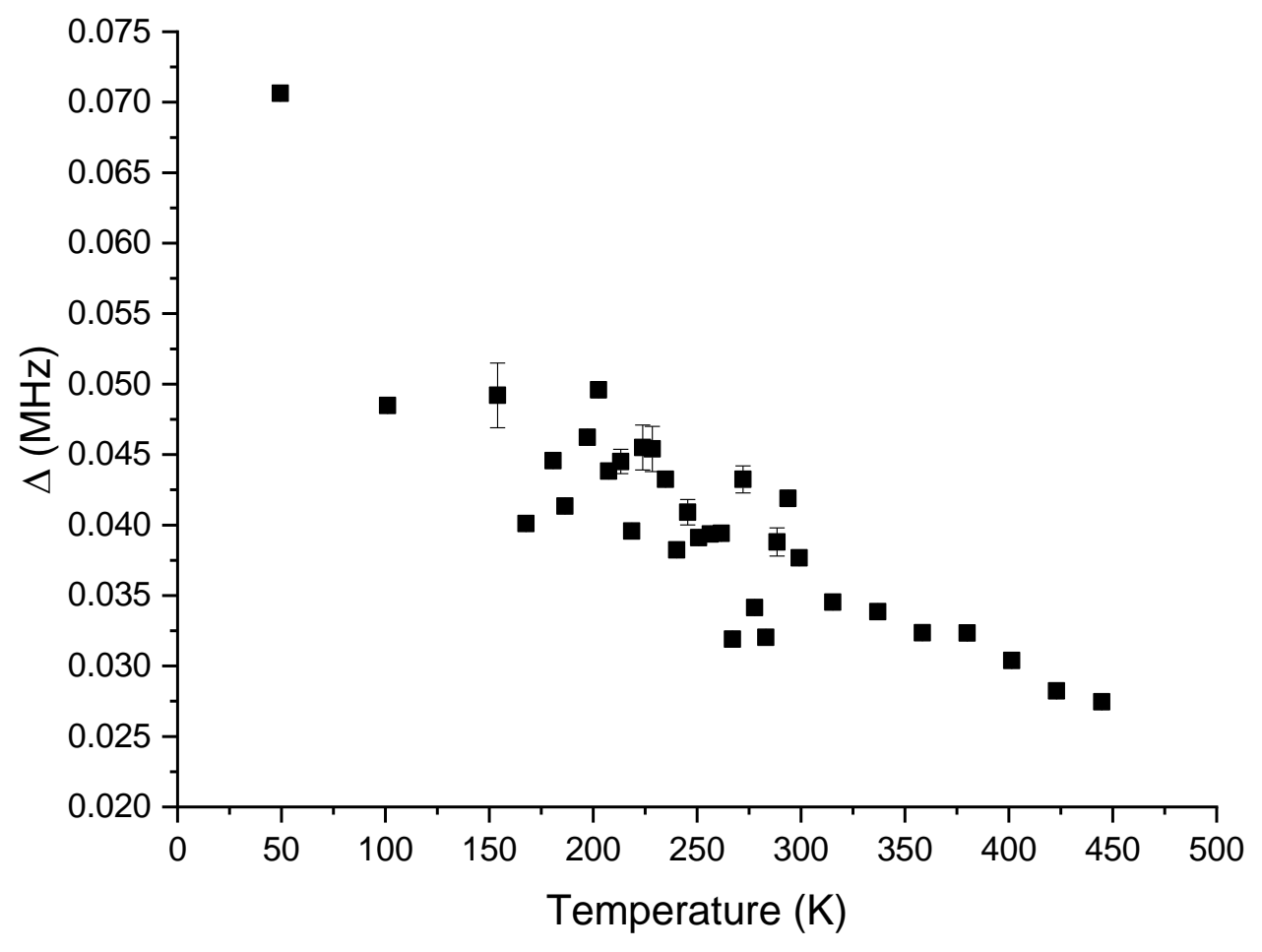


Figure S26: Raw muon decay asymmetry data from inverted $\left(\mathrm{Mn}_{0.41} \mathrm{Mg}_{0.59}\right)\left[\mathrm{Mn}_{1.59} \mathrm{Mg}_{0.41}\right] \mathrm{O}_{4}$ spinel at 200 and $400 \mathrm{~K}$ in zero magnetic field

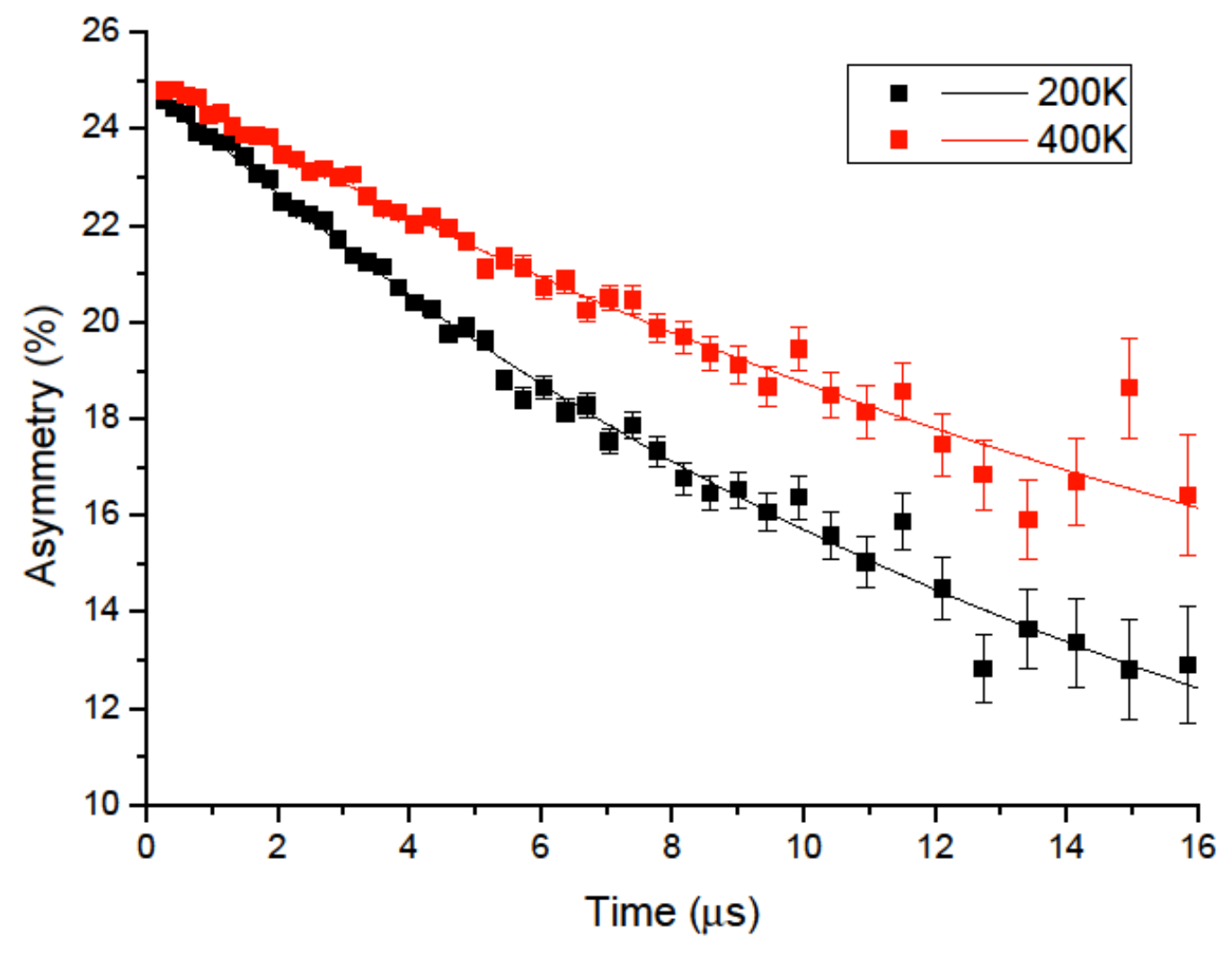


Figure S27: Muon spin relaxation rate $\lambda$ in inverted $\left(\mathrm{Mn}_{0.41} \mathrm{Mg}_{0.59}\right)\left[\mathrm{Mn}_{1.59} \mathrm{Mg}_{0.41}\right] \mathrm{O}_{4}$ spinel

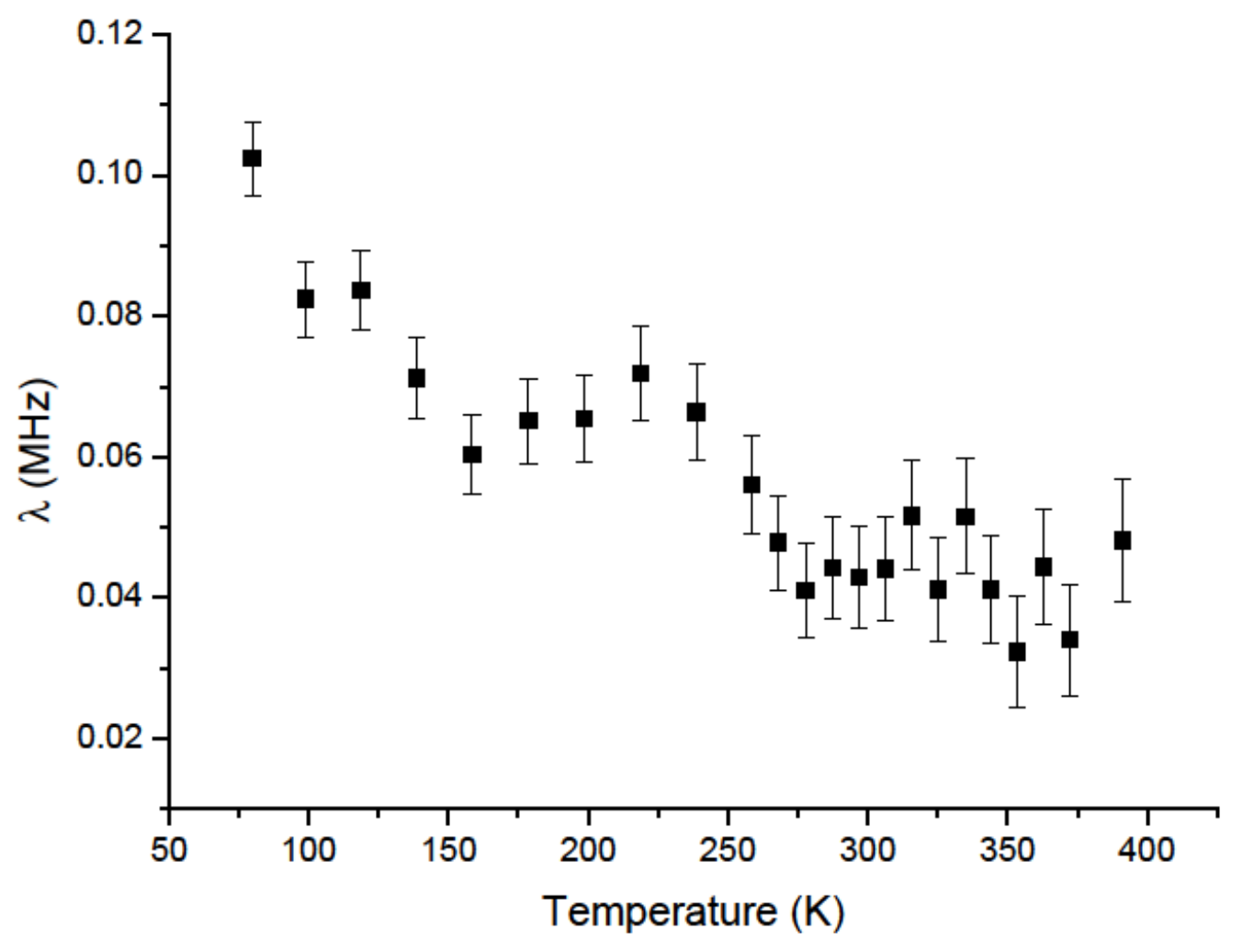


Figure S28: (a) local $\mathrm{Mg}$ environment, (b) energetics of $\mathrm{Mg}$ diffusion pathway in spinel lattice from DFT computations

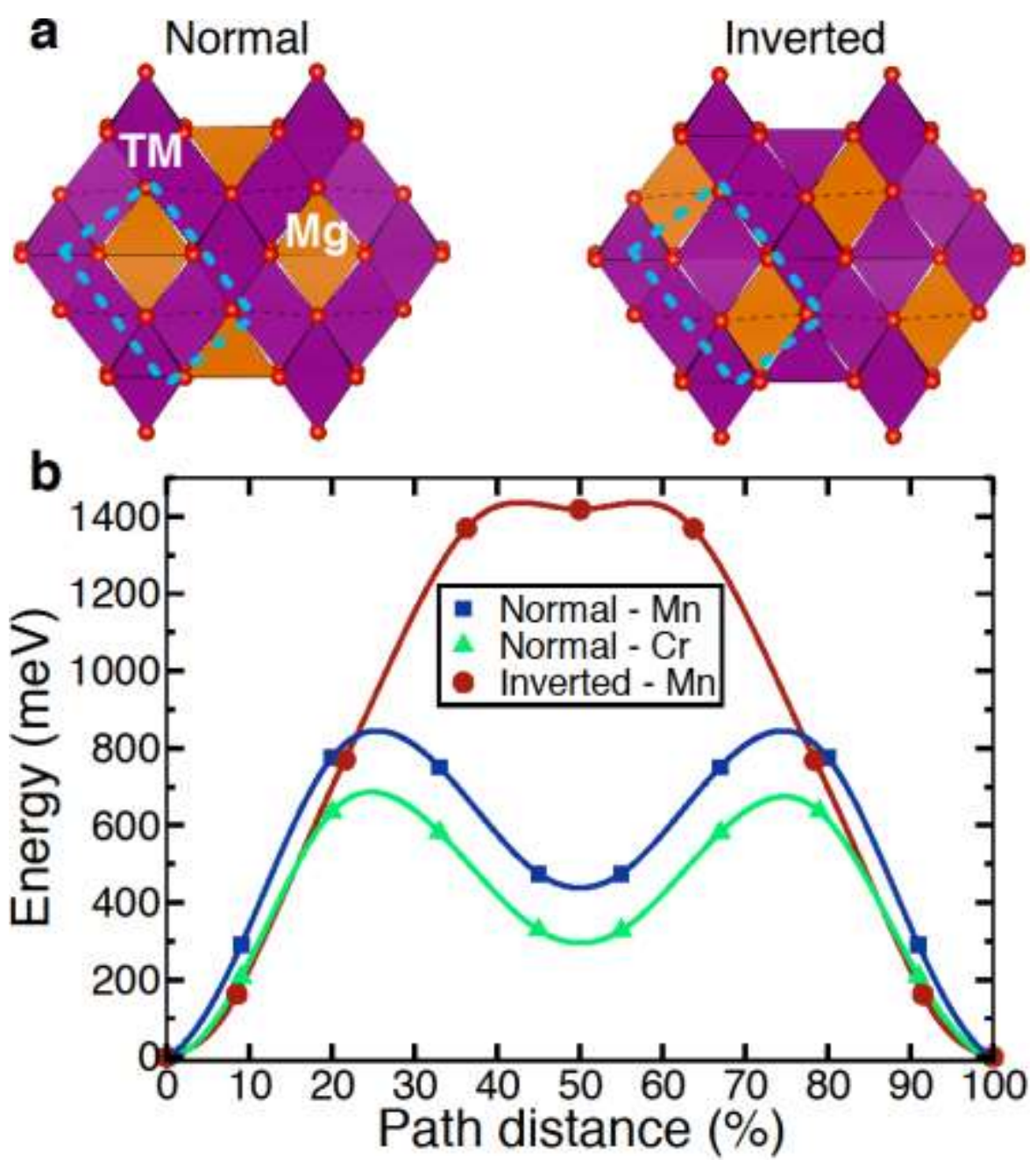


Figure S29: TEM EDX of (a) pristine and (b) CV-charged sol-gel $\mathrm{MgCr}_{2} \mathrm{O}_{4}$. The atomic ratios of $\mathrm{Mg}$ and $\mathrm{Cr}$ extracted from quantification of the spectra are indicated.
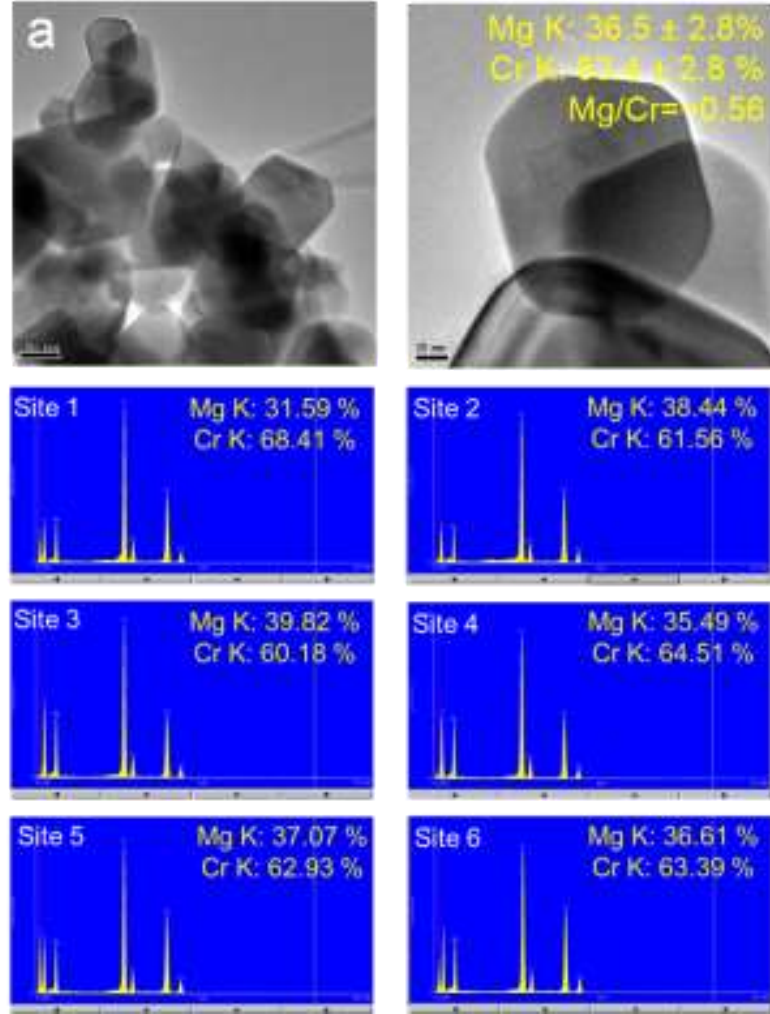
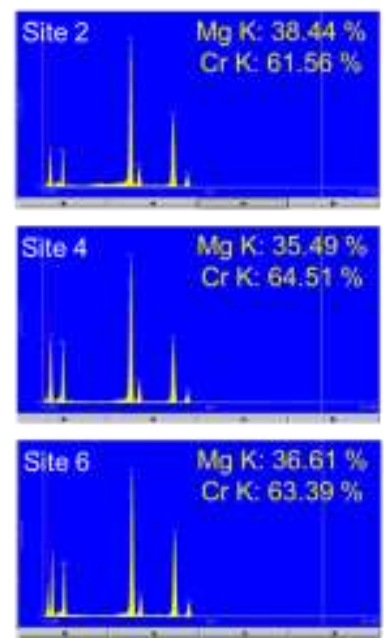
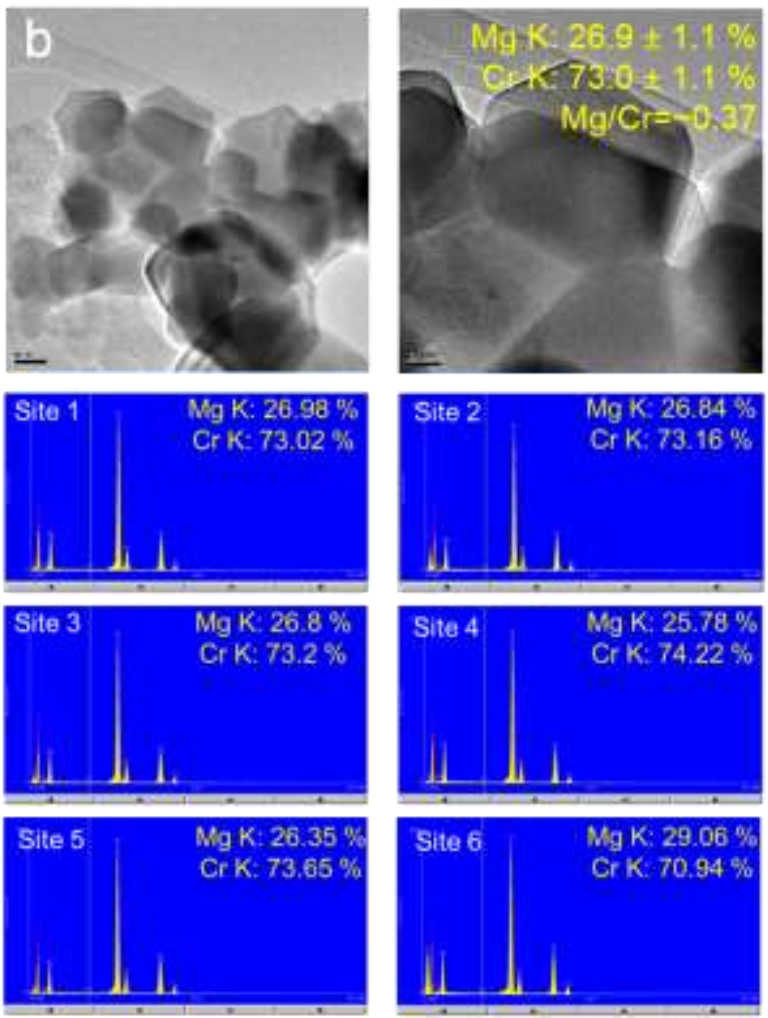
Figure S30: XRD of pristine and CV-charged sol-gel $\mathrm{MgCr}_{2} \mathrm{O}_{4}$.

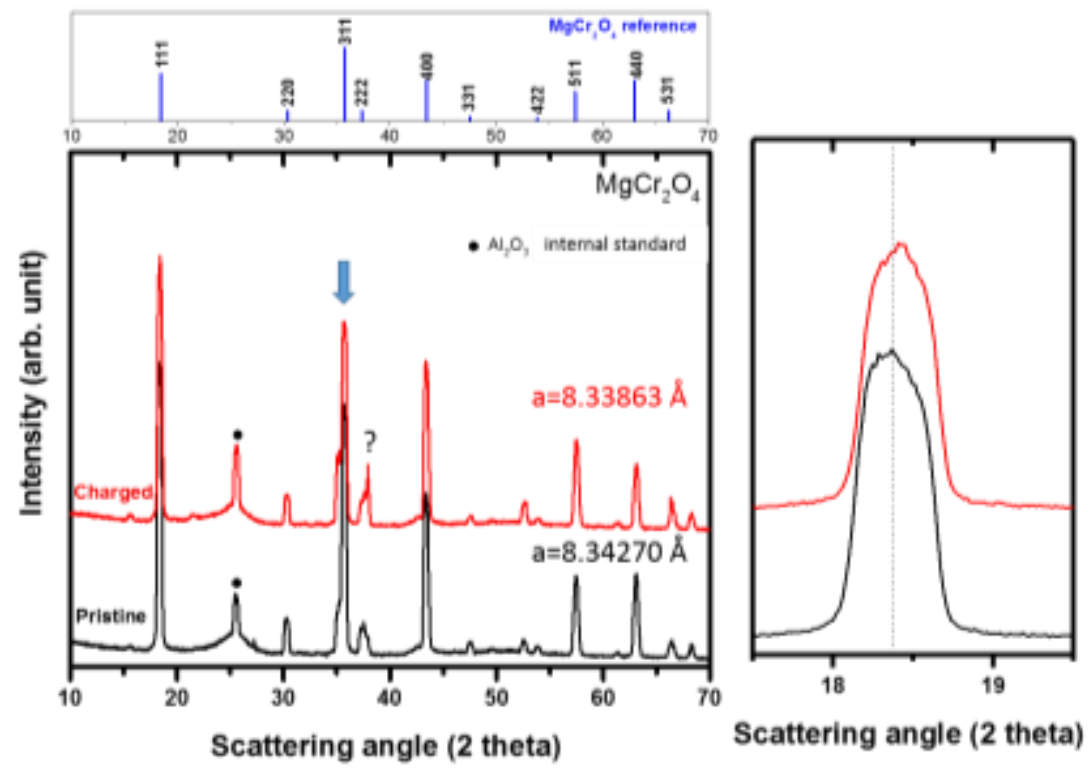


Figure S31: ${ }^{25} \mathrm{Mg}$ magic angle spinning (MAS) NMR of sol-gel $\mathrm{MgCr}_{2} \mathrm{O}_{4}$ after a CV charge (“ indicates $3^{\text {rd }}$ batch) and X-ray exposure, as indicated, collected at $11.7 \mathrm{~T}$. The plots were not subject to normalization. Consequently, peak areas/intensities do not follow $\mathrm{Mg}$ content changes between the samples. Variable scan numbers used for the plots.

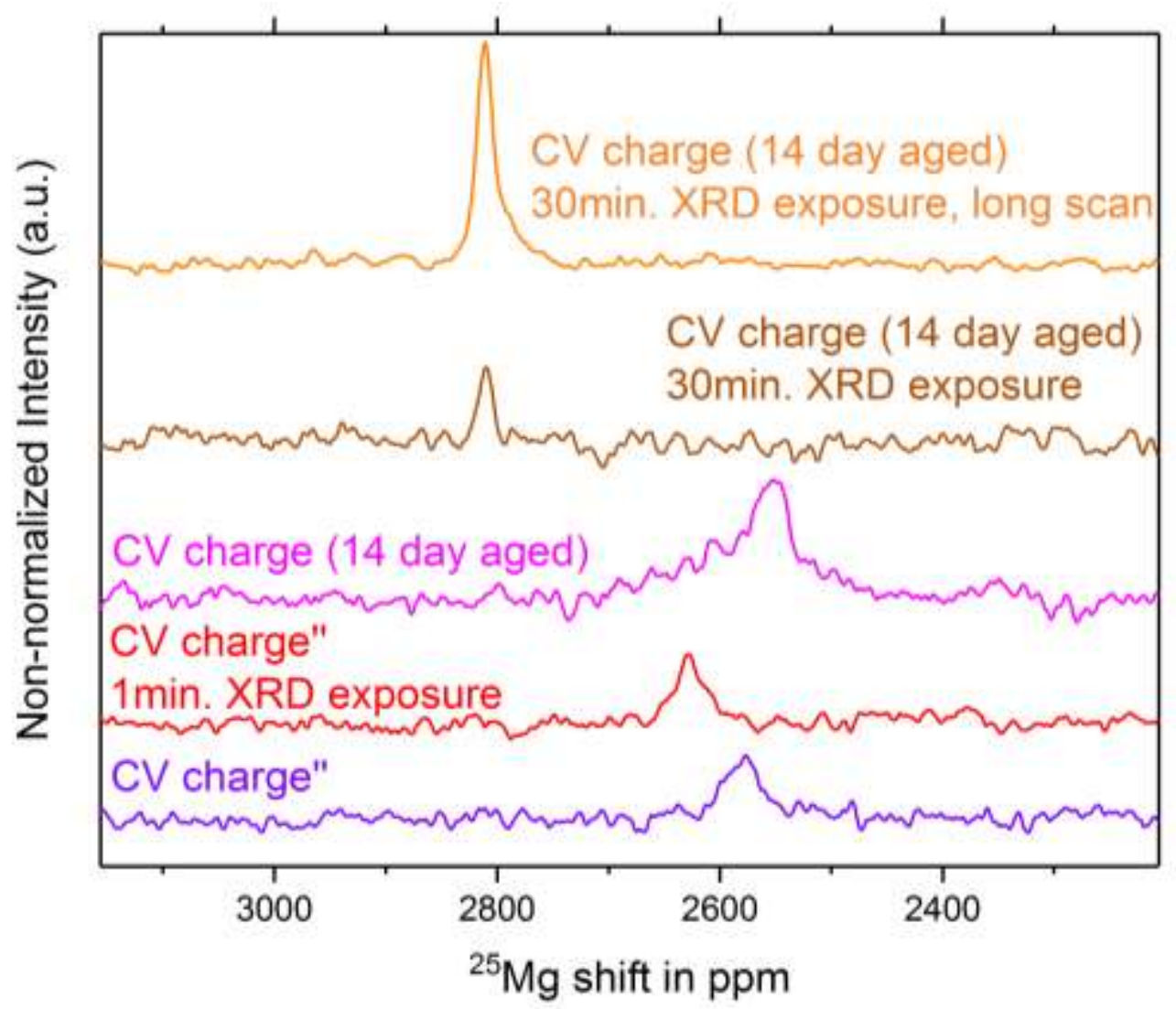

Solid State NMR was used quantitatively to probe electrochemical activity of $\mathrm{MgCr}_{2} \mathrm{O}_{4}$ (see Figure 4c) and the stability of the demagnesiated materials. Figure S33 shows the stability of charged materials vs. air and X-ray exposure. Total loss of $\mathrm{Mg}$ local order associated with $\mathrm{Cr}+4$ coordinations and reappereance of $\mathrm{Mg}$ local order in coordination with $\mathrm{Cr}+3$ is observed for a sample exposed to 30 minutes of lab X-ray source (typical $10-80^{\circ}$ scan on a Bruker D8 XRD with $\mathrm{Cu}$ target) whereas partial loss (about half) is observed after 1 minute exposure to a lab X-ray source ( 1 minute scan at $45^{\circ}$ on a Rigaku XRD with Co target). Similar total loss of charged species was separately confirmed for several samples post-XAS measurements (data not shown) which employ more powerful x-rays. Furthermore, a gradual loss was also observed upon air exposure. The "relaxation" behavior is also associated with an organic gassing, detected when opening several airtight NMR rotors with degrading samples, suggesting an oxidation process of the organic decomposition products post-charge could have been associated with the reduction of $\mathrm{Cr}+4$. This process appears to be enhanced by photoelectrons and/or abundance of excess oxygen (air exposure) as shown in Figure S34. 
Figure S32: ${ }^{25} \mathrm{Mg}$ magic angle spinning (MAS) NMR spectra evolution (top) of sol-gel $\mathrm{MgCr}_{2} \mathrm{O}_{4}$ after a CV charge (" indicates $2^{\text {rd }}$ batch), packed in an NMR rotor under air but then kept airtight and (bottom) sol-gel $\mathrm{MgCr}_{2} \mathrm{O}_{4}$ after a CC charge, kept in open air for 30mins prior to a quick acquisition. Spectra collected at $11.7 \mathrm{~T}$. Variable scan numbers used for the plots. While samples after charge showed evidence of $\mathrm{Mg}$ deintercalation, after aging, signals at shifts consistent with pristine $\mathrm{MgCr}_{2} \mathrm{O}_{4}$ were increasingly observed.
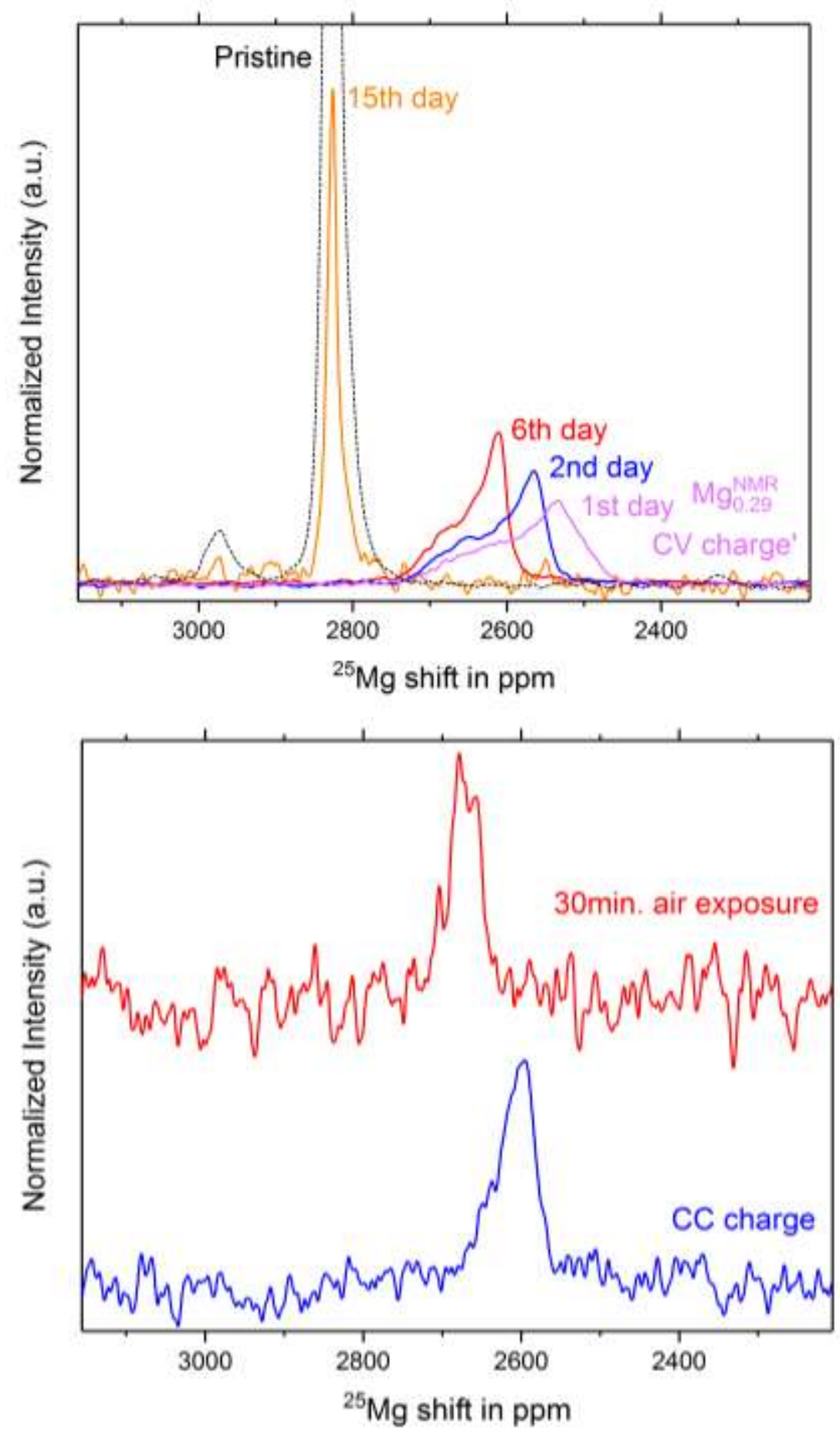
Figure S33: (a) Electrochemical profiles of cells with working electrodes containing normal $\mathrm{MgMn}_{2} \mathrm{O}_{4}$ and inverted $\left(\mathrm{Mn}_{0.41} \mathrm{Mg}_{0.59}\right)\left[\mathrm{Mn}_{1.59} \mathrm{Mg}_{0.41}\right] \mathrm{O}_{4}$, against a $\mathrm{Li}$ metal counter electrode, charged at constant current; both cells contained a Li-ion electrolyte. Comparison of the ${ }^{25} \mathrm{Mg}$ magic angle spinning (MAS) NMR of pristine and charged (b) normal $\mathrm{MgMn}_{2} \mathrm{O}_{4}$ and (c) inverted $\left(\mathrm{Mn}_{0.41} \mathrm{Mg}_{0.59}\right)\left[\mathrm{Mn}_{1.59} \mathrm{Mg}_{0.41}\right] \mathrm{O}_{4}$, collected at $11.7 \mathrm{~T}$; * indicates spinning sidebands.
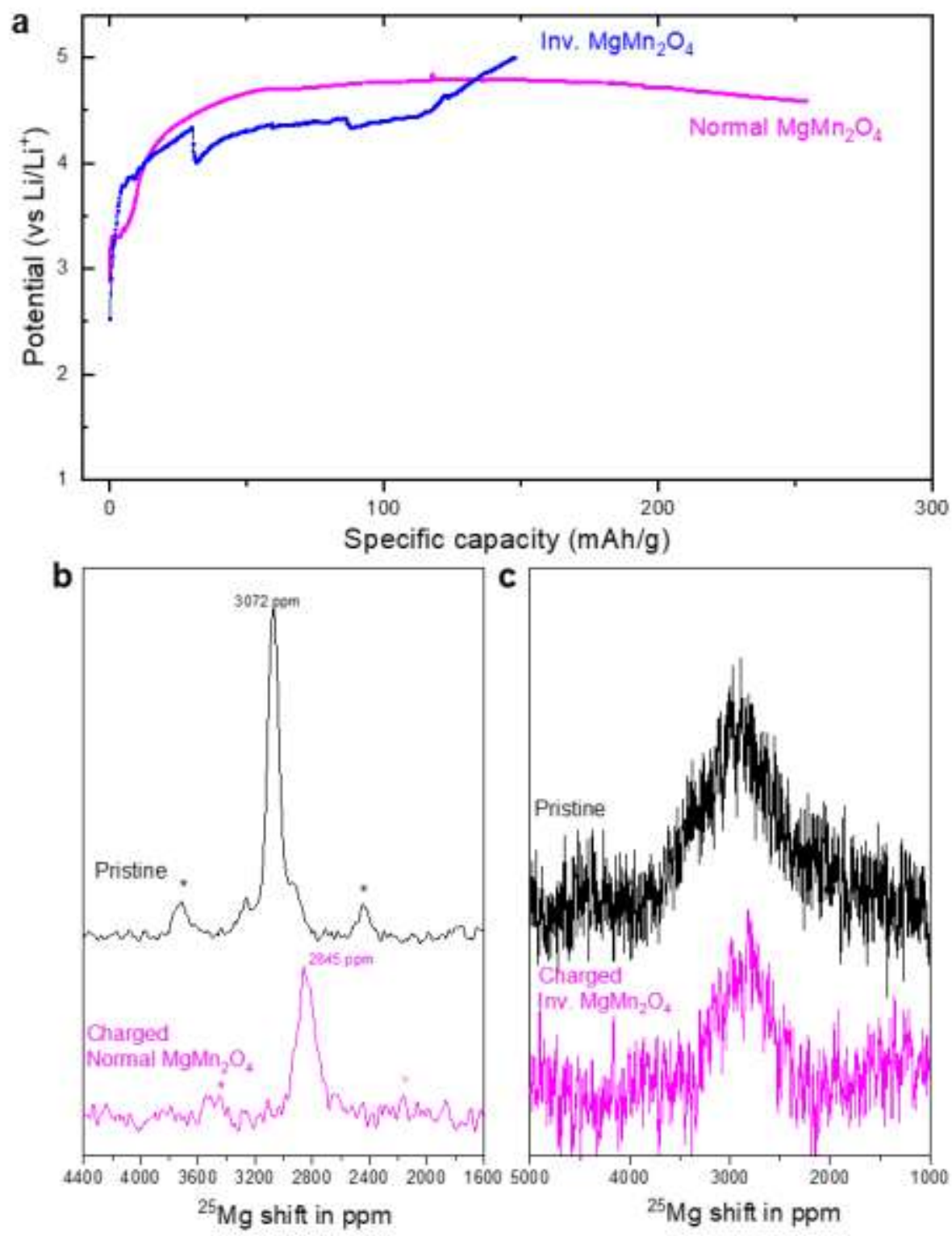